\title{
Substance-Abuse Treatment and Mortality
}

\author{
Author: Isaac Swensen
}

NOTICE: this is the author's version of a work that was accepted for publication in Journal of Public Economics. Changes resulting from the publishing process, such as peer review, editing, corrections, structural formatting, and other quality control mechanisms may not be reflected in this document. Changes may have been made to this work since it was submitted for publication. A definitive version was subsequently published in Journal of Public Economics, [VOL\# 122, (February 2015)] DOl\# http://dx.doi.org/10.1016/j.jpubeco.2014.12.008

Swensen, Isaac D. "Substance-Abuse Treatment and Mortality." Journal of Public Economics 122 (February 2015): 13-30. doi:10.1016/j.jpubeco.2014.12.008.

Made available through Montana State University's $\underline{\text { ScholarWorks }}$ scholarworks. montana.edu 


\title{
Substance-Abuse Treatment and Mortality* Isaac D. Swensen
}

December 2, 2014

\begin{abstract}
Drug-overdose deaths, which have more than doubled over the past decade, represent a growing public-health concern. Though substance-abuse treatment may be effective in reducing drug abuse, evidence for a causal effect of treatment on drug-related mortality is lacking. I analyze the effect of substance-abuse treatment on mortality by exploiting county-level variation in treatment facilities driven by facility openings and closings. The estimates indicate that a 10-percent increase in facilities lowers a county's drug-induced mortality rate by 2 percent. The estimated effects persist across individual and county characteristics and further indicate that spillovers of treatment reduce other related causes of death.
\end{abstract}

Keywords: Drug Abuse; Mortality; Substance-Abuse Treatment; Public Health; Health Economics

*Swensen is an assistant professor in the Department of Agricultural Economics and Economics, P.O. Box 172920, Montana State University, Bozeman, MT 59717-2920. Email: isaac.swensen@montana.edu. Phone: (406) 451-2991. 


\section{Introduction}

Over the past 11 years, 311,828 people have died from drug overdoses in the United States. ${ }^{1}$ Particularly alarming is the recent trend seen in Figure 1, showing annual drug induced deaths more than doubling over the past decade. Moreover, in 2009 drug-induced deaths overtook traffic accidents as the number one external cause of death, with 39,147 deaths (Kochanek et al., 2011). These increases have occurred over a time period when many other external causes of death were declining and when resources devoted to drug-control policies were increasing (ONDCP, 2005). ${ }^{2}$ Naturally, this has given rise to intense debate regarding the merits of intervention policies designed to limit drug abuse and its consequences. The primary objective of this paper is to analyze the effect of one such intervention—-substance-abuse treatment—and its impact on drug-induced deaths.

Policies intending to reduce costs associated with drug abuse typically concentrate on either supply-side enforcement, such as law-enforcement efforts to disrupt the illegal distribution of controlled substances, or a demand-side approach such as treatment or prevention. To date, federal spending primarily targets drug-supply-reducing policies, including law enforcement, interdiction, and international relations (ONDCP, 2005). However, a large body of research suggests that these policies are ineffective at reducing drug abuse (Dinardo, 1993; Miron, 1999; Kuziemko and Levitt, 2004; Dobkin and Nicosia, 2009; Dobkin, Nicosia and Wienburg, 2013; Cunningham and Liu, 2003, 2005). ${ }^{3}$ Moreover, where researchers find reductions in drug-related outcomes due to enforcement efforts, they are typically temporary and, arguably, costly relative to alternatives. For example, Dobkin and Nicosia (2009) examine what they consider to be "quite possibly the DEA's greatest success in disrupting the supply of a major illicit substance," analyzing the effect of a major disruption in the supply of methamphetamine precursors in 1995. They find a temporary effect on drug prices, health outcomes and drug-related arrests-with drug prices returning to pre-intervention levels in four months and other outcomes recovering within 18 months. More

\footnotetext{
${ }^{1} 1999$ through the end of 2009.

${ }^{2}$ For information on other preventable deaths see CDC WONDER online database, 2002-2009.

${ }^{3}$ Related studies also evaluate the price-elasticities of illicit drugs (Chaloupka and Saffer, 1999; Caulkins and Reuter, 1998).
} 
recently, Dobkin, Nicosia and Wienburg (2013) find no changes in methamphetamine consumption or drug-related arrests associated with state laws targeting over-the-counter medicine used to produce methamphetamine. Also examining enforcement policies, Kuziemko and Levitt (2004) find that the overall effect of dramatic increases in drug-offender incarceration rates from 19851996 led to a small reduction in related crime, and conclude that such law-enforcement policies are likely not cost-effective. ${ }^{4}$

Substance-abuse treatment offers a promising alternative approach to drug control. ${ }^{5}$ Moreover, it is a particularly relevant policy in light of changes brought about by the Affordable Care Act, which requires all health insurance sold on the exchanges to include services for substance-use disorders and increases funding for these services (Buck, 2011). That said, researchers have yet to demonstrate a causal effect of substance-abuse treatment in reducing drug-related outcomes among the general population. Empirical obstacles arise primarily due to the concealed nature of illicit-drug markets and the poor quality and availability of drug-use and treatment data. As such, analyses of substance-abuse treatment often rely on small samples of self-reported substance use and adverse consequences pre- and post-treatment. In such cases, attributing post-treatment changes in drug-related outcomes to treatment gives rise to serious concerns regarding bias induced by selection and the propensity for individuals entering treatment to regress to the mean. ${ }^{6}$ Moreover, in studies where randomization is possible such as randomized controlled trials, the findings are often difficult to generalize to broad populations due to small sample sizes or a narrow focus on specific treatment approaches and/or select demographic groups.

These limitations aside, there are good reasons to believe that substance-abuse treatment can reduce drug abuse and related activities. Clinical trials research consistently finds significant declines in drug use associated with all major modalities of treatment (Brewer et al., 1998; Griffith

\footnotetext{
${ }^{4}$ In related work, Dinardo (1993) finds no evidence that regional and time variation in drug seizures influence cocaine use or the price of cocaine and Saffer, Chaloupka, and Dave (2001) analyze state spending on both supply and demand-side drug-control policies and argue that drug treatment spending may be a relatively efficient method to reduce drug abuse.

${ }^{5}$ Prevention is another primary demand-side intervention. In recent work, Anderson (2010) finds no effect of an aggressive anti-methamphetamine advertising campaign on youth methamphetamine use.

${ }^{6} \mathrm{~A}$ notable exception is Lu and Mcguire (2002), who consider the marginal productivity of outpatient treatment using an instrumental variables approach. They find a decrease in drug use associated with increased time in treatment.
} 
et al., 2000; Pendergast et al., 2002). Suggestive evicence from economic-evaluation studies show that the benefits of treatment far outweigh the costs and that treatment is less costly than alternative drug-control policies such as incarceration or policing. ${ }^{7}$ For example, Rydell and Everingham (1994) compare treatment and enforcement methods to reduce cocaine abuse using three evaluation criteria: consumption costs, number of users, and total societal costs. In each case they find a significant advantage for treatment, arguing that 34 million dollars in treatment has roughly the same impact as 246 million dollars devoted to enforcement strategies.

Despite the potential for substance-abuse treatment to improve public health, questions about its efficacy remain. A common concern is that addictive behaviors may be unresponsive to treatment as evidenced by low completion rates $(44 \%)$ and a high likelihood of relapse (SAMHSA, 2009). Moreover, there are concerns that treatment may not reach those in need, as court-referred treatment admissions displace voluntary clients who are arguably more likely to benefit (Hser et al., 2007). ${ }^{8}$ In addition, community groups often oppose local services for drug users, citing perceived concerns for personal security (Tempalski, 2007). Taken together, these issues question the efficacy a treatment-based approach to drug control and highlight the need to understand the underlying relationship between investments in treatment and drug-related consequences.

This study contributes to these policy debates by documenting the causal effect of substanceabuse treatment provision on mortality. Specifically, I use county-level data on the number of substance-abuse treatment facilities to evaluate the effects of access to treatment by considering the degree to which drug-induced death rates change when treatment facilities open and close. My identification strategy leverages within-county variation in the number of substance-abuse treatment facilities over a period of 10 years (1999-2008), spanning 48 states. These panel data allow me to include a rich set of fixed effects (county and state-by-year) and control variables (demographics and measures of economic conditions) in my models, so the estimates are identified based

\footnotetext{
${ }^{7}$ For reviews of related literature see Cartwright (2000), McCollister and French (2003).

${ }^{8}$ On the other hand perhaps the most problematic users and those most likely to benefit from treatment are those referred by the criminal justice system. Drug courts were first introduced in 1989 and have since spread to all 50 states, totaling 2,147 operating courts in 2008 (Stinchcomb, 2010). In 2007, 37 percent of reported admissions in the Treatment Episodes Data Set were referred to treatment from the criminal justice system (SAMHSA, 2009).
} 
on plausibly exogenous variation. I also conduct several ancillary analyses in support of the validity of this research design, including an analysis that demonstrates that outcomes in a county change after but not before the number of facilities change. Finally, I offer evidence of an underlying mechanism associated with treatment by analyzing the effect of variation in the number of treatment facilities on substance-abuse treatment admissions.

The analysis reveals that increasing access to treatment through additional treatment facilities significantly reduces mortality. The reduction is most prominent among drug-induced deaths, though I do find some evidence of positive spillovers of treatment as facilities reduce other causes of death closely related to drug abuse. The main results indicate that a net increase of one facility reduces a county's annual drug-induced mortality rate by 0.4 percent, suggesting that a 10 percent increase in the number of facilities lowers a county's drug-induced mortality rate by 2 percent. That the estimates are persistent across demographic and socio-economic groups suggests that the benefits of treatment are quite broad.

My approach, which shifts the focus from the effects of substance-abuse treatment on those who receive treatment to the effects of substance-abuse treatment facilities on the communities they serve, offers several important contributions. First, it allows me to obtain estimates that reflect the effects of treatment on patients and the spillover effects onto the broader community. In so doing, my estimates allow for more comprehensive cost-benefit considerations. Second, it allows me to consider the effects of treatment on mortality - a severe-but infrequent outcome that tends to be beyond the scope of randomized control trials. Third, the use of county-level U. S. data allows me to obtain estimates that reflect the effects of treatment facilities across the United States. To my knowledge this is the first nationwide analysis documenting the causal benefits of substance-abuse treatment on mortality.

The remainder of this paper proceeds as follows. In Section 2, I discuss several key features of the market for substance-abuse treatment and relevant background on drug-overdose deaths. I describe the data and introduce the empirical methodology in sections 3 and 4. In Section 5, I present the main analysis on drug-induced mortality and the analysis of effects on other causes 
of death in Section 6. In Section 7, I explore the determinants of facility openings and closings and in Section 8, I show estimates using an alternative data source and an analysis of the effect of treatment facilities on treatment admissions. Finally, I conclude and discuss the implications of the results in Section 9.

\section{Background}

According to the National Survey of Drug Use and Health, nine percent of Americans age 12 or older (23.1 million) have used an illicit drug in the past month. Over 7 million are specifically classified as dependent abusers of an illicit substance such as marijuana/hashish, cocaine (including crack), heroin, hallucinogens, inhalants, or prescription-type psychotherapeutics (SAMHSA, 2011a). An estimate of the economic costs of drug use-measured in terms of crime, health and productivity-totaled more than $\$ 193$ billion in 2007 (NDIC, 2011). Though substance-abuse treatment is a promising avenue to reduce these costs, treatment rates for those in need remain very low. In 2010, 90 percent of those classified as substance dependent or substance abusing did not receive treatment, with commonly cited barriers to treatment being cost constraints and a lack of insurance coverage. ${ }^{9}$

Evidence also indicates that capacity constraints are an important barrier to the delivery of treatment to those in need. For example, Dave and Mukerjee (2011) analyze the effect of state legislation that reduces out-of pocket costs for mental health and substance-abuse treatment and find a relatively small effect on treatment admissions. They argue that the effect on admissions is muted, in part, because of treatment capacity constraints. ${ }^{10}$ As capacity limits the delivery of

\footnotetext{
${ }^{9}$ From 2007-2010, 38 percent of individuals making an effort to get treatment, but not receiving it report health coverage and cost as a primary reason. Other reported reasons for not receiving treatment include "not ready to stop using (30.3 percent), able to handle the problem without treatment (9.0 percent), no transportation/inconvenient ( 8.4 percent), might have negative effect on job (7.9 percent), had health coverage but did not cover treatment or did not cover cost (7.4 percent), might cause neighbors/community to have negative opinion ( 7.1 percent), and did not feel need for treatment at the time (6.5 percent)" (SAMHSA, 2011a).

${ }^{10}$ The authors highlight supply and capacity constraints suggested by limited growth in the number of treatment facilities and increasing treatment waiting periods, which stand in stark contrast to the $35 \%$ increase in substancerelated emergency department visits and a growing gap between those needing and those receiving treatment.
} 
treatment, expansions in the number of facilities have the potential to increase substance-abuse treatment by relaxing this constraint. In addition, expansions in the number of treatment facilities may increase treatment by introducing new options and/or lower cost options to the community.

\subsection{Treatment Industry Background}

In this environment, the number of substance-abuse treatment facilities may be a particularly relevant policy parameter. In the United States, over 13,500 stand-alone treatment facilities are the primary setting for delivery of substance-abuse treatment, offering a wide range of drug-treatment programs and related services. ${ }^{11}$

The substance-abuse treatment industry includes profit, non-profit, and public providers, the bulk of which (87 percent) are privately-owned facilities. ${ }^{12}$ Though the objective functions of facilities may differ somewhat by ownership status, the decision to open a treatment clinic likely depends crucially on (i) a perceived need for treatment providers or an opportunity to improve upon currently offered treatment services and (ii) the ability to secure funding for treatment services from either public or private 3rd party payers (SAMSHA 2011b). Given existing capacity constraints and the high need for treatment, the financing of treatment providers is of particular relevance when considering the predictors of facility openings and closings.

Unlike general health care, which relies on funding through insurance mechanisms, substanceabuse treatment relies primarily on public funding in the form of federal block grants and state subsidies. That said, recent mental health parity legislation and the rise of managed-care contracts have increased the importance of public and private insurance revenue to providers (Horgan and Merrick, 2001; Olmstead and Sindelar, 2004). Assuming these sources of financing generally increase with drug abuse and related problems, analyses of the effect of treatment provision on drug-related outcomes may understate the actual effect of treatment.

\footnotetext{
${ }^{11}$ According to 2002-2008 National Survey of Substance Abuse Treatment Services (N-SSATS) data, 87 percent of facilities offering treatment are not located in or operated by a hospital, and 95 percent are licensed, certified, or accredited - typically by state health agencies/departments— to provide substance abuse treatment (SAMHSA, 2008). In terms of size, these facilities are generally quite small-treating 255 individuals annually.

${ }^{12}$ The breakdown of ownership type is 60 percent non profit, 30 percent for profit, and 10 percent public.
} 
The typical treatment episode includes detoxification and medically- and/or behaviorally-based treatment, followed by efforts to prevent or limit relapse after completion of treatment. ${ }^{13}$ Admission rates into these specialized treatment facilities are higher for individuals who are white, male, unemployed, and less educated (SAMHSA, 2008). ${ }^{14}$ According to the Treatment Episodes Data Set (TEDS), 96 percent of admissions relate to five main substances: alcohol (22 percent), alcohol with secondary drug abuse (18 percent), opiates (19 percent), marijuana/hashish (16 percent), cocaine (13 percent) and other stimulants ( 8 percent $).{ }^{15}$

Though an analysis of specific treatment programs is beyond the scope of this study, understanding several features of treatment provision offers insight into the potential for treatment to reduce substance abuse. The majority of treatment services occur in an outpatient setting-in which clients do not reside at the treatment site. ${ }^{16}$ Outpatient care delivers treatment programs and modalities, such as detoxification, methadone maintenance, regular outpatient, adolescent outpatient, and drug-court programs (SAMHSA, 2009). For more serious substance-abuse problems, facilities provide residential treatment in which clients temporarily live at the treatment site (e.g. inpatient detoxification, chemical dependency programs, therapeutic communities). While treatment modalities vary substantially and often target particular demographic groups or specific drug addictions, all modalities share similar goals to mitigate the consequences of drug abuse and encourage healthier lifestyles.

\subsection{The Rise of Drug-Induced Mortality}

These treatment-based efforts may be one way to reduce the rising tide of drug abuse in the United States. Drug-overdose deaths - a particularly costly consequence of drug abuse-have increased

\footnotetext{
${ }^{13}$ In many cases, treatment facilities include ancillary services such as substance-abuse education, outreach activities, counseling, self-help groups, mental health services, and others (SAMHSA, 2008).

${ }^{14}$ In the United States, high rates of substance abuse or dependence are present across most demographic groups. That said, abuse rates are relatively higher among individuals aged 18-25, males, less educated, and those living in larger metropolitan areas (SAMHSA, 2011a).

${ }^{15}$ The remaining 4 percent of admissions are related to sedatives, tranquilizers, hallucinogens, PCP, inhalants, over the counter medications, and other unreported drugs.

${ }^{16}$ Outpatient treatment services account for 90 percent of reported clients. The remaining admissions are provided in residential ( 9 percent) and hospital inpatient (1 percent) settings (SAMHSA, 2008).
} 
sixfold since 1980, with the most recent increases being largely attributable to a rise in prescriptiondrug abuse such as opioid analgesics (e.g. morphine, codeine, hydrocodone, oxycodone, fentanyl, and methadone). ${ }^{17}$ For instance, over the past decade prescription opioid-related deaths have tripled and accounted for 40 percent of all drug-poisoning deaths in 2008. In the same year, heroine and cocaine_common recreational drugs_-together account for approximately 20 percent of drug-poisoning deaths (Warner et al, 2011).

In light of these trends, it is perhaps surprising that drug-induced mortality receives little attention within either the context of treatment or analyses of other drug-control interventions. For instance, in a recent review of opioid-dependence therapies Amato et al. (2005) highlight that mortality is "seldom taken into account to assess the efficacy of treatments [due to the lack of long-term follow up in clinical trials]."

\section{Data}

My main analysis uses data on the number of substance-abuse treatment facilities available in the U.S. Census Bureau's County Business Patterns (CBP). CBP data report the annual number of substance-abuse treatment clinics (a single physical location) in each U.S. county for both outpatient and residential facilities from 1999-2008. ${ }^{18}$ Though I show estimates separately by residential and outpatient facilities, my main analysis combines outpatient and residential classifications, using the total count of establishments as an indicator for county-level provision of substance-abuse treatment. As such the estimates will reflect the comprehensive effect of substance-abuse treatment facilities on mortality rates.

To calculate drug-induced mortality rates, I use restricted-use National Center for Health Statistics Multiple Cause of Death Data and population data from the National Cancer Institute's Surveil-

\footnotetext{
${ }^{17}$ In the case of prescription drug abuse-where the majority of drug abusers obtain drugs from family or friendstypical supply-side interventions may be less effective relative to strategies such as treatment (SAMHSA, 2011).

${ }^{18}$ The following six-digit NAICS codes identify treatment establishments: 621420 — "Outpatient mental health and substance abuse centers" and 623220_- "Residential mental health and substance abuse facilities." Many of these facilities also offer mental health services, though according to the $2008 \mathrm{~N}$-SSATS only 8 percent of known facilities indicate a primary focus on mental health services.
} 
lance Epidemiology and End Results (Cancer-SEER) program. ${ }^{19}$ I measure drug-induced mortality using causes of death with specific reference to drug-induced poisoning, identified by the 10th revision of the International Classification of Diseases codes (ICD-10). ${ }^{20}$ Over the sample, drugpoisoning deaths average 25,286 annually and account for nine out of ten deaths categorized by the Center for Disease Control and Prevention (CDC) as drug induced. ${ }^{21}$ Notably, drug-poisoning deaths are a relatively acute outcome, plausibly responsive to annual changes in treatment availability and are not inclusive of deaths that result from adverse effects of properly administered substances, such as an allergic reaction to a prescribed dosage, where we would not expect treatment to have a meaningful impact.

I limit my analysis to U.S. counties with at least one treatment facility over the 1999-2008 time period and counties with available identifiers in the 48 contiguous states. ${ }^{22}$ The resulting data include drug-induced mortality and treatment facility data for 2,408 counties in 48 states, spanning 10 years. $^{23}$

In Table 1 I present summary statistics for measures of substance-abuse treatment facilities and drug-induced mortality rates used in the main analysis. Table 1 indicates an average of 47.51 facilities and 9.4 annual drug-induced deaths per 100,000 residents. Importantly, there is substantial variation in the number of facilities, the average county experiences 2.23 net openings and 1.08 net closings annually from 1999 to 2008 . Column (1) also shows relatively high drug-induced mortality rates for males, whites, and individuals ages 15-64.

\footnotetext{
${ }^{19}$ As reported by Stevens et al. (2011), the Cancer-SEER population data are more accurate than data interpolated from the Census because they "are based on an algorithm that incorporates information from Vital statistics, IRS migration files, and the Social Security database." The Cancer-SEER population data are also used to construct countyby-year demographic controls.

${ }^{20}$ See Appendix Table A2 for a breakdown of ICD-10 codes used in this analysis. This measure of drug-induced deaths also includes alcohol poisonings, which account for 1.2 percent of drug-induced deaths.

${ }^{21}$ The remaining CDC categories of drug-induced causes include deaths from chronic drug use, leading to medical conditions such as mental and behavioral disorders or other long-term drug-induced diseases which may not be responsive to annual changes in treatment provision. For a complete list of deaths categorized as drug induced by the CDC see Kochanek et al. (2011).

${ }^{22}$ Specifically, I drop all counties in $\mathrm{HI}$ and $\mathrm{AK}$ in addition to 14 total counties in MT, VA, CO, and FL, where county identifiers are inconsistent or unavailable. I assume zero facilities when none are reported in a given year.

${ }^{23}$ Over the same time-frame, the aggregate number of facilities increases from 12,019 to 15,411 .
} 


\section{Empirical Strategy}

As alluded to above, my empirical strategy identifies the effects of substance-abuse treatment facilities using year-to-year variation within counties driven by facility openings and closings. I first estimate a simple model that relates a county's drug-induced mortality rate to its number of treatment facilities:

$$
\text { Mortalityct }_{c}=\alpha_{c}+\alpha_{t}+\theta \text { Facilityct-1 }+\epsilon_{c t},
$$

where Mortality M $_{\text {is }}$ the drug-induced mortality rate per 100,000 residents in county $c$ in year $t, \alpha_{c}$ and $\alpha_{t}$ are county and year fixed effects, Facilityct-1 is the number of substance-abuse treatment facilities in county $c$ in year $t-1$, and $\epsilon_{c t}$ is a random error term that I allow to be correlated within counties over time in obtaining standard error estimates. My primary measure of facilities is the count of substance-abuse treatment facilities lagged one time period-implicitly assuming that previous year changes in the number of facilities impact current year drug-induced deaths. My use of mortality rates and facility counts is motivated by the relative ease of interpretation with linear models as well as the nontrivial fraction of zero outcomes, which limits the usefulness of $\log$ models. ${ }^{24}$ That said, I also show that the results are similar using alternative approaches including Poisson and log models (adjusted for zero counts).

Eq. (1) includes county fixed effects to account for fixed county characteristics that may correlate with drug-induced mortality. So, for example, inherent differences between urban and rural counties or time-invariant measures of county public services and drug-control policies will not confound the estimates. Year fixed effects are included to account for aggregate time-varying shocks such as aggregate economic conditions and changes in the national drug-control strategy. My main results are based on regressions that weight by the relevant population size in order to improve efficiency, though I also consider unweighted regression models following Solon, Haider, and Woolridge (2013).

\footnotetext{
${ }^{24}$ Another alternative-using rates on the left as well as the right-would introduce bias into the estimate of $\theta$ as the denominators are collinear.
} 
Using this baseline approach, $\theta$ measures the extent to which a county's drug-induced mortality rate deviates from its average as the number of treatment facilities changes within that county, controlling for common shocks. If $\hat{\theta}$ is the causal effect of one additional treatment facility, one must assume that the annual variation in the number of treatment facilities within a county is orthogonal to other determinants of drug-induced mortality. I relax this assumption in Eq. (2) by controlling for state-by-year fixed effects and a rich set of county-by-year controls. That is, I estimate the following regression equation:

$$
\text { Mortalitycst }_{c}=\alpha_{c}+\gamma_{s t}+\theta \text { Facility }_{c s, t-1}+\beta X_{c s t}+\epsilon_{c s t}
$$

where the notation is similar to Eq. (1), $\gamma_{s t}$ are state-by-year fixed effects, and $X_{c s t}$ is a set of county-by-year controls, including the unemployment rate, firm births, per-capita income, and the fraction of the county population that are: white, black, male, less than 18 years old, 18-64 years old, and greater than 64 years old..$^{25}$

State-by-year fixed effects flexibly control for state-specific shocks such as changes in statelevel policy measures influencing drug-abuse. For example, these controls will account for yearto-year changes in funding for health and law-enforcement services which typically originate at the state or federal level.

Eq. (2) also controls for year-to-year changes in county-year covariates including demographic composition and local economic conditions. Including demographic controls speaks to the concern that age-, race-, or gender-related compositional changes in a county's population may affect drug-induced mortality rates and investments in treatment. The controls for unemployment rates, incomes and firm births account for the possibility that my outcome and treatment facilities may both be related to local economic conditions. ${ }^{26}$ These controls account for the possibility that

\footnotetext{
${ }^{25}$ I have also considered specifications controlling for the number of law-enforcement officers and county-level measures of crime. Though the results remain unchanged with the addition of these controls, they are not included in my analysis in light of potential endogeneity concerns. These results are available upon request.

${ }^{26}$ County unemployment rates are from the BLS Local Area Unemployment Statistics. Firm births include all county-level firm births reported by the U.S. Census Statistics of U.S. Businesses. Per capita income was obtained from the Bureau of Economic Analysis Local Area Personal Income Data.
} 
treatment facilities and drug-induced deaths are correlated with local economic conditions. In particular, existing studies indicate that unhealthy behaviors and mortality are typically pro-cyclical; with mortality-rates and unhealthy behaviors such as alcohol consumption, smoking and physical inactivity increasing in response to better economic conditions (Ruhm 2005, 2006). ${ }^{27}$ Inasmuch as drug-induced mortality follows a similar pattern and facility openings are pro-cyclical, excluding these controls would lead to a downward bias.

The set of controls included in Eq. (2) address most concerns about omitted variables that may be systematically related to drug-induced mortality and the number of treatment facilities; however one could argue that other unobservable factors may confound the estimates. Following Altonji, Elder, and Taber (2005), I assess the degree to which unobservable factors are likely to confound the estimates by examining the degree to which the estimates are sensitive to the inclusion of controls for observable factors related to the outcome. For instance, if the estimates are not particularly sensitive to the inclusion of the county-year covariates described above, it would suggest that related unobserved variables are unlikely to threaten identification. The results of this assessment are discussed in detail in Section 5.1.

I also conduct several ancillary analyses in order to support the validity of the research design and exogeniety assumption of treatment facilities. First, I estimate a version of Eq. (2) that also considers the number of facilities in the current year and the subsequent year. This analysis, presented in Section 5.2, serves to address concerns regarding reverse causality, or that changes in the number of treatment facilities may be driven by recent changes in drug abuse and related outcomes. As another way of lending support to the validity of the research design, in Section 6 I estimate the effects of additional facilities on other causes of death. While this should not be thought of as a typical falsification exercise, as treatment may have far-reaching effects on health, one would expect the effects to be greatest for causes of death that are most closely related to drug abuse. Finally, in Section 7, I consider a model using all of my covariates and additional demandside characteristics to predict changes in the number of facilities in order to offer a more in-depth

\footnotetext{
${ }^{27}$ Mortality also increases with income receipt as measured by transfer payments, tax rebates, and social security benefits (Dobkin and Puller, 2007; Evans and Moore, 2010).
} 
consideration of the determinants of facility openings and closings.

An outstanding concern is whether or not individuals seek treatment outside the border of their county of residence. Given the that the the average county has 48 facilities and that 90 percent of admissions occur in an outpatient setting requiring frequent travel to the facility, it seems reasonable to assume that most treatment occurs within the county of residence. That said, inasmuch as crossing county borders to seek treatment does occur, the estimates would understate the effect of a treatment facility.

Using the specification outlined in Eq. (2), the estimate of $\theta$ is the extent to which changes in a county's drug-induced mortality rate (relative to its average) respond to changes in the number of facilities, controlling for state-specific time shocks and other covariates. Despite the many advantages of this approach, there are some limitations that bear noting. First, my empirical approach, which focuses on county-level aggregates, implies that I will not be able to separate the effects of treatment facilities on those who receive treatment from the effects of treatment facilities on the broader community. That said, I view this as a reasonable tradeoff in order to be able to speak to the effects on the community as a whole. Second, while there is significant variation across facilities in the types of treatment that they offer, my main results will reflect an average of the effects of these facilities.

\section{Results}

\subsection{Effects on Drug-Induced Mortality}

In Table 2 Panel A I present regression results based on the models specified in Eq. (1) and Eq. (2). In columns (1) through (4) I show a progression of estimates, starting with the baseline model in Column (1) and leading to my most-flexible specification in Column (4). Including county and year fixed effects, the estimate in Column (1) suggests that an additional facility reduces a county's drug-induced mortality rate by 0.036 ( 0.39 percent $)$ per 100,000 residents and is significant at the one-percent level. In columns (2) through (4), I add state-by-year fixed effects as well as county- 
level time-varying controls for demographic changes, and local economic conditions. In Column (4), the estimate indicates a significant 0.42 percent decline in drug-induced mortality associated with an additional treatment facility. ${ }^{28}$ To put the magnitude into context, the estimate suggests that a 10 percent increase in the number of facilities decreases a county's drug-induced mortality rate by approximately 2 percent. The estimates together provide evidence that treatment, as measured by expansions in treatment facilities, does reduce drug-induced mortality. ${ }^{29}$

As alluded to previously, showing a progression of estimates is, in part, motivated by Altonji, Elder, and Taber (2005) who demonstrate that the degree to which estimates change with the inclusion of relevant observable variables is informative about the degree to which the estimates might be biased because the regression lacks controls for some relevant unobservable variables. As such, it is reassuring that the estimated effects of facilities across columns (2) through (4) are virtually unchanged when the set of demographic controls and controls for economic conditions are omitted from the regression.

I also show results using unweighted estimates in Appendix Table A3 in addition to estimates obtained using a Poisson model in Appendix Table A4. The estimates yield results similar to those in Table 2 Panel A. In particular, the Poisson estimate of -0.004 can be interpreted as a semielasticity, indicating that an additional facility reduces drug-induced mortality by approximately 0.4 percent, similar to the effect found using Eq. (2). ${ }^{30}$

In Table 2 Panel B, I show estimates separately considering changes in the number of residential and outpatient facilities. Separately estimating the effects by these classifications offers insight into the relative efficacy of treatment facilities by primary setting. ${ }^{31}$ For instance, a residential treatment setting offers a relatively high level of treatment intensity and often targets high-risk individuals

\footnotetext{
${ }^{28}$ Note that my measure of drug induced mortality includes unintentional, intentional, and unknown intent poisonings. Over seventy percent of these deaths are classified as unintentional poisonings. A further breakdown of this measure shows a 0.45 percent decline in unintentional poisonings, 0.4 percent decline in intentional poisonings, and a 0.2 percent decline in unknown intent poisonings.

${ }^{29}$ In Appendix Table A1 I show the full set of regression results for the specifications used in columns (2) through (4). Sensitivity analysis exploring higher order terms of the number of facilities do not yield evidence of a nonlinear relationship.

${ }^{30}$ In figures A3 and 5, I show similar results using log mortality (adjusted for zero outcomes).

${ }^{31}$ Although these classifications indicate the primary setting, it is worth noting that 35 percent of facilities offering residential care also offer outpatient care.
} 
with severe drug addiction (Reif et al., 2014). Alternatively, outpatient settings are typically lower cost than residential alternatives and account for 90 percent of treatment admissions (SAMHSA, 2008; Shepard et al., 2003). As such, it is perhaps not surprising that the estimates in Panel B indicate relatively large effects associated with changes in the number of outpatient facilities.

\subsection{Timing of Facility Openings}

I next show estimates based on a version of Eq. (2) that includes lags and leads of the number of treatment facilities. In addition to providing insight into the persistence of the effect, this analysis serves to address concerns that changes in the number of substance-abuse treatment facilities may be driven by recent changes in drug abuse and related outcomes. The results, shown in Table 3 , demonstrate that previous- and current-year changes in the number of facilities significantly reduce drug-induced mortality (columns 1 through 3), but that drug-induced mortality is not related to the number of facilities in future periods (Column 4). In particular, the results suggest that reverse causality is not a major concern and thus reinforces the causal interpretation of estimates based on Eq. (2).

For a subset of counties, I also plot drug-induced mortality rates leading up to and following a change in the number of facilities. Notably, this approach restricts the sample to relatively small counties with a single change in the number of facilities over several years. That said, it may offer additional insight into the extent to which the outcome is trending before the change in facilities.

In Figure 2 I first plot mortality rates of the 230 counties with a single net increase in facilities over a 6 year time span and county-year observations at least 3 years leading up to and 2 years following the net increase in the number of facilities. With the caveat that this is a very limited sample of counties, the results support the previous evidence that the outcome is not trending downward prior to the change and offers some evidence for a decrease in mortality following the increase in treatment facilities. I present a similar plot in Figure 3 focusing on counties with a single net decrease in facilities. Though the plots are relatively noisy and based on even fewer counties, the plots do not give rise to the concern that the outcome trends upward just prior to a 
decrease in the number of facilities. ${ }^{32}$

\subsection{Heterogeneous Responses to Treatment Facilities}

In tables 4 through 6, I explore potential heterogeneity across age, race, gender, and county characteristics. Documenting any differential effects of treatment provides useful information for public policy and practitioners of treatment and speaks to the possibility that my main results are driven by a particular demographic group. Moreover, as the mean incidence of drug-induced mortality differs by demographic characteristics, the percentage impact of an additional treatment facility provides insight into the receptivity of sub-groups to treatment. Accordingly, in the following sections, I also provide context as to the recent trends in substance abuse and treatment across different groups.

\subsubsection{Heterogeneity by Age}

As highlighted in Table 1, drug-induced mortality rates vary substantially across age categories. Figure 4 further emphasizes these differences, depicting the age profiles of these deaths and how they have changed over time. In particular, drug-induced mortality increases dramatically from 1999-2008 and follows a similar pattern-increasing then decreasing with age, with the highest mortality rates among the age 20-60 demographic. As such, the 20-60 age demographic is of particular interest when considering lives saved through treatment.

In Table 4, I present the estimated effects of treatment facilities on age-specific drug-induced mortality rates. Column (1) shows the combined estimate for all ages and columns (2) through (10) present the estimates in age bins of 10 years. Column (2) indicates no effect among children less than 10, which is not surprising as drug-induced deaths of young children are primarily accidental poisonings and should not respond to changes in the number of facilities. In contrast, the remaining estimates for individuals older than 10 — columns (3) through (10)—-suggest significant reductions in drug-induced mortality. Though the magnitudes of the point estimates generally increase then

\footnotetext{
${ }^{32}$ The results in figures 2 and 3 are similar when using counties with a single net increase over 1999-2008.
} 
decrease with age, there are no significant differences in the percentage impacts among individuals older than 10 years.

Perhaps contrary to our priors, expansions in treatment facilities also reduce drug-induced mortality among older populations (columns (8) and (9)). That said, from 2004-2009 substance-abuse treatment admissions of adults ages 50 or older have more than doubled, with older-adult treatmentadmission rates increasing relative to those of younger adults. ${ }^{33}$ These admissions are primarily driven by alcohol and prescription-drug abuse, though recent research suggests increasing use of illicit drugs, such as cocaine and heroin, among older adults (Arndt, Clayton, and Schultz, 2012). ${ }^{34}$

\subsubsection{Heterogeneity by Race and Gender}

I next explore the extent to which mortality rates by race and gender differentially respond to the number of treatment facilities. A breakdown by race is interesting as the type and severity of drug abuse often correlates with race and, as such, we may expect a differential response to treatment. Appendix Figure A1 Panel A plots race-specific drug-induced mortality rates over 1999-2008, showing white rates surpassing those for blacks beginning in 2002. These trends are consistent with recent increases in prescription-drug abuse primarily among whites and-prior to 2002relatively high black mortality rates corresponding with high rates of drug abuse (driven primarily by heroin and cocaine) among blacks. ${ }^{35}$

In Table 5, I show the estimated effects by race after displaying the estimate for the full sample in Column (1). The magnitude of the percentage impacts across columns (2) through (4) indicate a relatively large effect of an additional facility on drug-induced mortality among minorities. In particular, an additional treatment facility reduces black mortality rates by 0.48 percent. Given that there are relatively few blacks in many counties, I also consider estimates restricting the sample to

\footnotetext{
${ }^{33}$ In 2005, TEDS reports 4,622 treatment admissions for individuals age 70 or older. For a discussion of substanceabuse disorders in the elderly see Menninger (2002).

${ }^{34}$ To explore this issue further, in Appendix Table A5 I consider the effect of changes in the number of facilities on alcohol-poisoning mortality rates across age categories. The estimates suggest a significant reduction in alcoholpoisoning mortality rates primarily among older adults, with the largest effects among those ages 60-79. As such, reductions in alcohol-poisoning deaths account for at least a small part of the relatively large percentage impact on elderly adult drug-induced deaths in Table 4.

${ }^{35}$ For a discussion of trends in drug-induced deaths and drug abuse by race see Paulozzi and Annest (2007).
} 
counties within the highest tercile of proportion of county residents that are black (greater than 8 percent black). The estimates_-presented in Table A3 in the Appendix-indicate an even larger percentage impact (0.82) on drug-induced mortality rates among blacks.

I also estimate models using gender-specific mortality rates as the dependent variable. As highlighted in Table 1 and Panel B of Figure A1, drug-induced mortality rates are higher for males than females throughout 1999-2008. In addition, males account for 70 percent of reported treatment admissions (SAMSHA, 2009). That said, existing studies suggest that treatment initiation, completion, and time spent in treatment do not differ by gender (Green et al, 2002). The estimates, shown in columns (5) and (6) of Table 5, indicate a 0.4 percentage impact of treatment facilities on drug-induced mortality rates for males and females.

\subsubsection{Heterogeneity Across County Characteristics}

In Table 6, I show estimates stratified by county urban classification and per-capita income. The motivation for doing so is to consider differential effects of treatment facilities across place environmentswhich are linked to differences in substance abuse and related outcomes. In particular, abuse rates are generally higher in urban areas and among individuals with low socioeconomic status (SAMHSA, 2011a). That said, looking at drug-induced mortality across urban classifications, Figure A2 shows little difference between urban and rural counties.

After displaying the estimate based on the full sample, columns (2) through (3) separately consider the effect for large urban counties, medium and small urban counties, and rural counties, using the National Center for Heath Statistics (NCHS) urban-rural classification scheme for counties. Column (1) indicates an estimated effect of 0.39 in large urban counties (average population of 1.4 million), Column (2) shows a slightly smaller effect in medium and small urban counties (average population of 164,000), and Column (3) indicates no significant effect of treatment facilities in rural counties (average population of 30,000). Several potential reasons for the lack of an effect in rural counties may include relatively low substance-abuse rates, high stigma of seeking 
treatment, or relatively noisy drug-induced mortality rates in rural counties. ${ }^{36}$ Notably however, the larger counties considered in columns (1) and (2) account for approximately 85 percent of the total population covered by my sample of counties. ${ }^{37}$

In columns (4) through (6), the estimates are stratified by per-capita incomes, where "low income" counties are defined as those with average per capita incomes in the lowest tercile, and medium- and high-income counties are defined similarly. Though the results are relatively noisy for low-income counties, the estimates provide evidence that the effect of treatment facilities is relatively large in counties with low average per-capita incomes.

Broadly speaking, tables 3-5 offer suggestive evidence that particular demographic groups and place environments are more responsive to treatment interventions. That said, the percentage responses to treatment are typically similar in magnitude and-with few exceptions-negative and precisely estimated, suggesting that the benefits of treatment facilities are quite broad and not driven by any one group in particular.

\section{Effects on other Causes of Death}

In this section, I investigate whether treatment facilities affect other causes of mortality. Though it is likely that substance-abuse treatment affects other causes of death, the expected sign of the effect is unknown. On one hand, a decline in drug-induced deaths may lead to an increase in other causes of death consistent with the competing risks model (see e.g. Arthur, 1981; Honore and Lleras-Muney, 2006). In particular, a host of risk factors act as competing influences contributing to mortality. As such, we might expect a decrease in drug-induced deaths to lead to an increase in deaths related to competing mortality risks such as motor-vehicle accidents or suicides. On the other hand, and perhaps more likely, positive spillovers of substance-abuse treatment may lead to

\footnotetext{
${ }^{36}$ The average number of substance-abuse treatment facilities in large urban, medium/small urban and rural counties is, respectively, 122, 20 and 2.

${ }^{37}$ In Appendix Table A7 I also explore heterogeneity by counties above and below the median values of (i) druginduced mortality and (ii) number of per-capita treatment facilities. The magnitudes suggest relatively large effects in counties with high prevalence of drug-induced mortality and low-prevalence of per-capita treatment facilities, though the percentage responses do not yield significant differences.
} 
declines in other causes of death. Indeed, substance abuse has far-reaching effects on health, and drug-induced deaths are likely one of many causes responsive to treatment.

As such, an analysis of the effects on other causes of death should not be thought of as a typical falsification exercise. However, in the context of identifying an effect of substance-abuse treatment, the extent to which the effects on non-drug-induced causes of death are smaller in magnitude is informative regarding the validity of the research design. Moreover, to the extent that drug treatment does reduce other causes of death, we would expect there to be a link between these deaths and drug abuse.

In this setting — where the number of deaths across causes varies widely — a natural approach is to estimate a log-linear model, where the estimates represent the percentage effect of an additional facility on mortality rates. ${ }^{38}$ I show results from models using log mortality rates of individuals less than 65 years old as deaths of individuals over the age of 65 likely add considerable noise to the estimates among many of these causes of death. ${ }^{39}$ In particular, Figure 5 plots the estimated effects on drug-induced mortality, all causes, all causes excluding drug-induced deaths, and deaths associated with cardiovascular disease, cancer, infection / immune deficiency, other disease (respiratory, kidney and degenerative brain diseases), motor-vehicle accidents, suicide, and homicide. ${ }^{40}$ The estimates indicate a relatively large effect of facilities on drug-induced mortality rates, lending added confidence that the research design is identifying an effect of treatment. In particular, the estimated effect on drug induced mortality rates (.5 percent) suggests that these deaths are much more responsive to treatment facilities than any other cause of death.

That said, the estimates also provide evidence for positive spillovers of treatment leading to fewer deaths associated with infection / immune deficiency, suicide, and homicide. ${ }^{41}$ These deaths contribute to a decline in the all causes category in Figure 5 and have an established association

\footnotetext{
${ }^{38}$ To avoid dropping county-year observations with zero deaths, I replace zeros with ones before calculating the mortality rates. Results from Poisson regressions are similar to the results from the log-linear specification and are available upon request.

${ }^{39}$ Figure A3 shows similar effects using individuals of all ages.

${ }^{40}$ See Appendix Table A2 for specific ICD-10 codes used for each category. I define cause of death categories similar to Stevens et al., 2011.

${ }^{41}$ Appendix Table A8 shows similar results using the linear model specified in Eq. (2).
} 
with drug abuse and related risky behaviors. For instance, drug abusers-injection abusers in particular - are at a high risk for infection and, moreover, substance abuse is generally associated with immune deficiencies (Sacerdote, 2006; Hubbard et al., 1988; Stein, 1999.) A further breakdown of the ICD codes in the infection and immune deficiencies category reveals that hepatitis $\mathrm{C}$ is particularly responsive to the number of treatment facilities, where substance abuse is a known contributor (Khalsa et al., 2008). Similarly, there is a well-documented relationship between drug abuse and deaths related to suicide and homicide (Moscicki, 1995; Brownstein et al., 1992). Taken together, the estimates shown in Figure 5 suggest that treatment saves lives among other causes of death, consistent with positive spillovers of reduced drug abuse, but that the percentage impact is much larger for drug-induced deaths.

\section{Determinants of Treatment Facility Openings and Closings}

The previous analyses demonstrate that the estimated effect of an additional treatment facility (i) is not sensitive to the inclusion of county-level covariates, (ii) is consistent with an effect of treatment on mortality rather than the reverse, and (iii) is focused among causes of death related to drug abuse. Though these results support a causal interpretation of the estimates, it is potentially informative to consider a more in-depth analysis of the determinants of treatment facility openings and closings. As such, I next consider models using county-level covariates as well as additional measures of the demand for illicit drugs to predict changes in the number of facilities. In particular, this analysis offers insight into the degree to which treatment provision responds to changes in the demand for addictive substances. A priori it is reasonable to expect increases in substance-abuse treatment in response to more demand for addictive substances. Left unaccounted for, the positive relationship between the demand for addictive substances and drug-induced mortality would suggest that the estimates understate the effect of an additional treatment facility.

Table 7 shows estimates from models similar to Eq. (2), but using the number of treatment facilities as the dependent variable and focusing on the estimated correlations of economic, de- 
mographic, drug-related crime and law-enforcement measures. Column (1) reveals a positive relationship with the county population, the fraction of individuals in each age category (relative to individuals less than age 10) and the fraction of the population that are female and white, though these may also be correlated with other measures of socio economic status. Column (2) provides evidence that the number of facilities is procyclical, and columns (3) and (4) do not reveal significant correlations between the number of facilities and drug-related arrest rates or law-enforcement officers per 100,000 residents. Column (5) is generally consistent with columns (1) through (4). The reported F-statistics test the joint significance of the variables listed in each column, confirming that economic and, to a lesser degree, demographic measures are significant predictors of the number of facilities. As a whole, Table 7 shows evidence that the number of treatment facilities varies directly with county-level measures that are positively correlated with drug-related mortality. Inasmuch as facilities increase with measures that proxy for the demand for addictive substances and the county-level controls do not adequately account for these correlations, my main estimates shown in Table 2 would be understated. That said, the insensitivity of the estimates in Table 2 to the inclusion of county-level controls suggests that this is unlikely.

\section{Estimates Using Alternative Data on Treatment Facilities}

The following section estimates models using several additional data sources in order to explore heterogeneity by facility characteristics, provide insight into an underlying mechanism associated with treatment, and to lend added support to the previous estimates. These data sources are described in detail in sections 8.1 and 8.2.

\subsection{N-SSATS Data}

As an alternative source for the number of substance-abuse treatment facilities in each county, I use data from the National Survey of Substance Abuse Treatment Services (N-SSATS)—a survey administered to "all organized substance abuse treatment facilities known to SAMHSA" [Sub- 
stance Abuse and Mental Health Services Administration]. Though N-SSSATS provides valuable facility-specific details not available in CBP data, it has several shortcomings. In addition to being voluntary survey-based data, N-SSATS spans a shorter time-period than CBP data and does not correspond to the calendar year_-instead providing a count of facilities at varying reference dates. In the analysis, I use N-SSATS data from 2002-2008 - throughout which there is a consistent reference date of March. Figure A4 compares the aggregate number of facilities in CBP and N-SSATS data, highlighting the shorter time span and fewer facility counts in N-SSATS data.

These shortcomings noted, the detail available in N-SSATS offers several advantages. Unlike the CBP data, which report the annual stock of facilities, N-SSATS tracks each facility over time allowing me to separately consider the effects of openings and closings. As the benefits of treatment may persist after a facility closes (i.e. patients may avoid post-treatment relapse or seek continuation of treatment at another facility) we may not expect a symmetric response to openings and closings.

N-SSATS also offers rich detail on facility characteristics. In addition to showing separate estimates for inpatient and outpatient facilities_-similar to the those presented in Table 2 using CBP data-I use the detail in the N-SSATS to consider estimates by facility size, ownership type and public-funding status. These analyses may be informative in light of potential differences in the efficacy of treatment or types of services offered that vary by facility characteristics. In terms of facility ownership, private non-profit organizations account for 60 percent of all facilities, followed by private for-profit organizations (30 percent), and government-operated facilities (approximately 10 percent). ${ }^{42}$

N-SSATS data also separately identify funded and unfunded facilities, which is important when I consider the effect of facilities on substance-abuse treatment admissions. That is, treatment admissions data are largely only available for publicly-funded facilities. Therefore, unlike CBP data,

\footnotetext{
${ }^{42} \mathrm{~N}-\mathrm{SSATS}$ reports a similar breakdown of actual client admissions across ownership types. As ownership type does not uniquely identify a particular type of treatment service, estimates by ownership type do not speak to the efficacy of specific treatment options. That said, several pronounced differences include a more balanced range of types of care offered by private non-profit facilities, a relatively specialized treatment approach by private for-profit facilities, and a relatively small fraction of private for-profit facilities willing to offer treatment at no charge to eligible clients (N-SSATS, 2008).
} 
using N-SSATS data provides the ability to consider the effect of an additional funded facility on treatment admissions into funded facilities. As alluded to in the industry background, most treatment facilities rely on public funding for substance-abuse treatment provision.

\subsection{TEDS Data}

Substance-abuse treatment admissions data come from the Treatment Episodes Data Set (TEDS). TEDS includes information on approximately 2 million annual substance-abuse treatment admissions collected by SAMHSA from state administrative systems. While publicly available by Metropolitan Statistical Area, in this analysis I use a special tabulation of TEDS which includes county-level admissions from 2002-2008. In these data, an admission is the initiation of a treatment episode in a non-hospital facility, where the duration of an episode can vary from days to months depending on the the type of service and completion of treatment. ${ }^{43}$

As alluded to previously, TEDS is not a census of all substance-abuse treatment admissions. With the exception of a few states, these data represent admissions into facilities receiving funds distributed through the state alcohol and/or drug agencies for the provision of substance-abuse treatment. Due to several differences in state reporting requirements, I restrict the sample to states that require publicly-funded facilities to report all treatment admissions, in total dropping 4 states from my analysis of treatment admissions (Arkansas, Colorado, Maryland, and Massachusetts). ${ }^{44,45}$

Using N-SSATS and TEDS data, I employ sample restrictions similar to my main analysisfocusing on U.S. counties with at least one treatment facility from 2002-2008, counties within the 48 contiguous states and dropping counties with inconsistent or unavailable county identifiers. I also restrict the analysis to non-hospital facilities that are licensed providers of substance-abuse

\footnotetext{
${ }^{43}$ As facilities may admit an individual multiple times within the calendar year, the admission count does not necessarily represent unique individuals.

${ }^{44}$ The resulting sample includes 43 states.

${ }^{45}$ While approximately 60 percent of all facilities do receive public funds, there remain substantial differences in state-reporting requirements that introduce uncertainty as to the fraction of all admissions accounted for by TEDS. For instance, some states report only publicly-funded admissions instead of all admissions in facilities receiving funding. Also, some states allow voluntary reporting of admissions by unfunded facilities.
} 
treatment. In Table 8 I show summary statistics for the full N-SSATS sample in Column (1) as well as the sample used to analyze TEDS admissions data in Column (2). These statistics are largely similar to those in Table 1, with Column (2) also reporting average of county-level treatment admissions by treatment setting.

\subsection{Effects on Drug-Induced Mortality}

Analogous to Table 2, I first estimate the effect of changes in the number of treatment facilities on a county's drug-induced mortality rate. Using the models specified in Eq. (1) and Eq. (2), Table 9 Panel A presents these estimates, starting with the most parsimonious model in Column (1) and concluding with my most flexible specification in Column (5). The estimates across columns (1) through (5) closely resemble those based on CBP data, similarly indicating a significant effect of treatment facilities on drug-induced mortality rates. In particular, Column (6) indicates that that an additional facility reduces a county's drug-induced mortality-rate by 0.395 percent—slightly smaller than the impact in Table 2 (0.419 percent). In Panel B, I show estimates from models separately considering openings and closings. I define a facility opening as the first year a facility reports to N-SSATS and a closing as the last reporting year. ${ }^{46}$ Facility Opening and Facility Closing are running counts of openings and closings, and, as such, the estimates are identified off of variation in the number of openings and closings from year to year. The estimates in Panel B indicate that effect of treatment facilities is primarily driven by facility openings, suggesting that the effect of treatment persists beyond a facility closing.

\subsection{Effects on Drug-Induced Mortality, by facility characteristics}

Taking advantage of the detail in the N-SSATS data, I next show estimates from models that consider facilities separately by treatment setting, ownership type, size, and funding status. An assumption underlying this approach is that the number of facilities across characteristics are not jointly determined. To the extent that they are, the estimates on individual facility characteristics

\footnotetext{
${ }^{46}$ To reliably identify closings I use 2002-2007 N-SSATS data.
} 
would be less reliable due to collinearity between facilities with different characteristics. With that caveat in mind, these estimates do shed light on potential differential effects correlated with particular types of facilities, whereas my main estimates reflect an average effect across all facility characteristics. $^{47}$

In Table 10 Column (1) I show estimates by treatment setting. Consistent with Table 2 Panel $\mathrm{B}$, the estimates reveal a relatively large mortality response to changes in the number of facilities offering outpatient services. The estimates in Column 2, which separate changes in facilities by ownership type, reveal a significant reduction in drug-induced mortality associated with increases in private-non-profit facilities. This is not surprising as these facilities account for the bulk of treatment facilities and admissions. Though the estimate is noisy and variation in public facilities is limited, the estimates also imply a relatively large effect associated with expansions in public facilities.

I proxy for facility size using a facility's average annual admissions. In light of the high utilization and capacity constraints of existing facilities, the average annual admissions likely reflect the size or capacity of a facility. ${ }^{48}$ Column (3) shows the estimates by large, medium, and small facilities, defined using terciles of annual average admissions. Though the estimates are quite noisy, the magnitudes are consistent with the effect of an additional facility increasing with facility size. ${ }^{49}$

Finally, Column (4) considers estimates separately by funded and unfunded facilities. This breakdown is primarily motivated by the fact that admissions data, which I use in the subsequent section, are only available for funded facilities. That said, there are several interesting differences between funded and unfunded facilities including a higher likelihood of public and private nonprofit facilities to receive public funds and a higher likelihood for unfunded providers to of-

\footnotetext{
${ }^{47}$ In separate analysis I have verified that these estimates are not particularly sensitive to county-level controls and do not behave erratically with alternative sample restrictions, suggesting that they are useful to consider the degree to which these characteristics provide differential effects on mortality.

${ }^{48}$ I use average annual admissions instead of admissions in a single year because annual admission reports are often missing or imputed within N-SSATS.

${ }^{49}$ I consider a related exploration of facility size using CBP employment data as a proxy for facility size. The analysis is limited as only employment ranges are consistently reported in the CBP, increasing the potential for mismeasurement. That said, the results, shown in Appendix Table A9, are also largely consistent with the effect of an additional facility increasing with facility size.
} 
fer specialized treatment services more commonly funded by out of pocket payment (Horgan and Merrick, 2001). As seen in Table 8, the majority of facilities do receive public funding. The estimates in Column (4) indicate that the effect on mortality is focused among changes in the number of funded facilities.

\subsection{Effects on Treatment Admissions}

I next estimate the effect of changes in the number of publicly-funded facilities on treatment admissions into publicly-funded facilities. While the coefficient on the number of funded facilitiescorresponding to my measure of treatment admissions-is of particular interest, I also control for changes in the number of unfunded facilities. That is, funded-facility admissions are likely not independent of the number of unfunded facilities. ${ }^{50}$ For instance, an additional unfunded facility may decrease reported admissions into funded facilities as individuals opt towards treatment at the unfunded facility. In this case, not accounting for changes in unfunded facilities would lead to a downward bias in the estimated effect of an additional funded facility. Alternatively, if increases in funded facilities correspond with decreases in unfunded facilities, the estimate may overstate the effect of an additional funded facility on treatment admissions.

As such, Table 11 presents estimates separately accounting for the number of funded and unfunded facilities. I once again employ a specification similar to Eq. 2, using the number of total, outpatient and inpatient admissions per 100,000 residents as the dependent variables. Columns (1) through (3) indicate that additional funded treatment facilities increase treatment admissions into funded treatment facilities and that the effect is driven by increases in outpatient admissions.

It is important to note that admissions provide one potential mechanism whereby treatment facilities may affect drug-induced mortality. Other mechanisms-including perceptions toward treatment or factors influencing the quality and accessibility treatment-may also contribute to

\footnotetext{
${ }^{50}$ In recent work, Cohen, Freeborn, and McManus (2013) consider the market for outpatient substance-abuse treatment in small rural counties and find that public outpatient clinics crowd out their privately-owned counterparts. As private facilities are less likely to receive funding, this further stresses the importance of controlling for the number of unfunded facilities in my specifications.
} 
declines in substance abuse. On the margin it is not clear which mechanisms are most important in reducing fatal overdoses. That treatment admissions do respond to the number of facilities, the estimates in Table 11 can be thought of as "proof of concept," demonstrating that treatment facilities lead to a change in an underlying factor associated with treatment. That said, given these many potential mechanisms and that these estimates are based on a subset of facilities, one should not interpret the estimated effect of treatment facilities on drug-induced mortality in the context of treatment admissions.

\section{Discussion and Conclusion}

The recent dramatic rise in drug-overdose deaths has become an increasingly important publichealth concern. In this paper, I provide evidence for the efficacy of substance-abuse treatmentas measured by treatment facilities-in reducing these deaths. My main specification suggests that increasing the number of treatment facilities by 10 percent would lead to a 2 percent decline in the drug-induced mortality rate. The estimates are robust across a range of individual and county characteristics, though the benefits of treatment facilities are more pronounced among racial minorities, in urban counties, and in counties with low per-capita incomes. Offering evidence that the expansion of facilities is associated with an underlying mechanism of treatment, I show that an additional treatment facility leads to an increase in treatment admissions. My results also suggest indirect benefits of treatment in reducing other causes of death likely related to drug abuse.

Although openings and closings of substance-abuse treatment facilities are not random, my ancillary analyses support a causal interpretation of these results. In particular, my empirical approach tests the sensitivity of the results to the inclusion of county-level covariates and alternative specifications, offers insight into predictors of facility openings, speaks to concerns for reverse

causality, demonstrates that the effect is focused among causes of death related to drug abuse, and highlights similar results obtained using an alternative data source.

Together, the estimates indicate that an additional facility reduces mortality by 1.5 total deaths 
in the average county each year. ${ }^{51}$ Considering these mortality benefits alone, a back of the envelope calculation suggests that the economic value of expansions in treatment facilities exceeds the associated costs. In particular, facilities average 255 annual admissions at an average cost of $\$ 2,515$ per admission. ${ }^{52}$ Given the average total annual cost of operating a facility $(\$ 641,325)$ and the estimated reduction in mortality (1.5 deaths), the cost of saving one life is approximately $\$ 427,550$ which is far less than the accepted range of estimates for the value of a statistical life. ${ }^{53}$

As a whole, these results offer encouraging evidence for the efficacy of substance-abuse treatment in reducing drug-related deaths. These findings are particularly relevant given existing concerns regarding the merit of current enforcement policies. Moreover, as mortality is a relatively infrequent consequence of drug abuse, the estimates may only capture a small portion of the benefits of substance-abuse treatment. As such, these findings also highlight the need to better understand the extent to which treatment can affect other drug-related outcomes such as crime, labor productivity, and child abuse.

\footnotetext{
${ }^{51}$ Based on Column (2) of Table A8 and an average weighted county population of 1,095,337.

${ }^{52}$ The average total annual cost of operating a facility is calculated by multiplying the average total cost of an admission by the average annual admissions. The average annual admissions are calculated using 2002-2008 NSSATS data and the costs of admission are from the Alcohol and Drug Services Study (ADSS), which are based on a nationally representative sample of substance-abuse treatment facilities (Shepard et al., 2003). The ADSS cost of an admission includes estimated total fixed and variable costs of providing a treatment admission.

${ }^{53}$ For example, Viscusi and Aldy (2003) find that the median value of a statistical life (VSL) in the US is approximately $\$ 7$ million and Aldy and Viscusi (2008) estimate age-group specific VSLs as follows: \$3.2 million (ages 18-24), \$9.9 million (25-34), \$9.9 million (35-44), \$8 million (45-54) and \$3.8 million (55-62).
} 


\section{References}

Aarons, G.A., S.A. Brown, M.T. Coe, M.G. Myers, A.F. Garland, R. Ezzet-Lofstram, A.L. Hazen, and R.L. Hough. 1999. "Adolescent Alcohol and Drug abuse and Health." Journal of Adolescent Health, 24(6): 412-421.

Aldy, J.E., and W.K. Viscusi. 2008. "Adjusting the Value of a Statistical Life for Age and Cohort Effects." The Review of Economics and Statistics, 90(3): 573-581.

Amato, L., M. Davoli, C.A. Perucci, M. Ferri, F. Faggiano, and R.P. Mattick. 2005. "An Overview of Systematic Reviews of the Effectiveness of Opiate Maintenance Therapies: Available Evidence to Inform Clinical Practice and Research.” Journal of Substance Abuse Treatment, 28(4): 321-329.

Anderson, D.M. 2010. "Does Information Matter? The Effect of the Meth Project on Meth Use among Youths." Journal of Health Economics, 29(5): 732-742.

Arndt, S., R. Clayton, and S.K. Schultz. 2012. "Trends in Substance Abuse Treatment 19982008: Increasing Older Adult First-Time Admissions for Illicit Drugs." American Journal of Geriatric Psych, 19(8): 704-711.

Arthur, W.B. 1981. "The Economics of Risks to Life." The American Economic Review, 71(1): 54-64.

Brewer, D.D., R.F. Catalano, K. Haggerty, R.R. Gainey, and C.B. Fleming. 1998. "A MetaAnalysis of Predictors of Continued Drug Use During and After Treatment for Opiate Addiction." Addiction, 93(1): 73-92.

Brownstein, H.H., H.R.S. Baxi, P.J. Goldstein, and P.J. Ryan. 1992. "The Relationship of Drugs, Drug Trafficking, and Drug Traffickers to Homicide." Journal of Crime and Justice, 15(1): 25-44.

Buck, J.A. 2011. "The Looming Expansion and Transformation of Public Substance Abuse Treatment under the Affordable Care Act.” Health Affairs, 30(8): 1402-1410.

Cartwright, W.S. 2000. "Cost-Benefit Analysis of Drug Treatment Services: Review of the Literature." The Journal of Mental Health Policy and Economics, 3(1): 11-26.

Caulkins, J., and P. Reuter. 1998. "What Price Data Tell Us about Drug Markets." Journal of Drug Issues, 28: 593-612.

Cohen, A., B. Freeborn, and B. McManus. 2013. "Competition and Crowding-Out in the Market for Outpatient Substance Abuse Treatment.” International Economic Review, 54(1): 159-184.

Cunningham, J.K., and L.M. Liu. 2003. "Impacts of Federal Ephedrine and Pseudoephedrine Regulations on Methamphetamine-Related Hospital Admissions." Addiction, 98(9): 12291237.

Cunningham, J.K., and L.M. Liu. 2005. "Impacts of Federal Precursor Chemical Regulations on Methamphetamine Arrests.” Addiction, 100(4): 479-488. 
Dave, D., and S. Mukerjee. 2011. "Mental Health Parity Legislation, Cost-Sharing and SubstanceAbuse Treatment Admissions.” Health Economics, 20(2): 161-183.

DiNardo, J. 1993. "Law Enforcement, the Price of Cocaine and Cocaine Use." Mathematical and Computer Modeling, 17(2): 53-64.

Dobkin, C., and N. Nicosia. 2009. "The War on Drugs: Methamphetamine, Public Health, and Crime." The American Economic Review, 99(1): 324.

Dobkin, C., N. Nicosia and M. Weinberg. 2013. "How Effective are Enforcement Efforts Targeting Illegal Drugs?" Unpublished Manuscript.

Dobkin, C., and S.L. Puller. 2007. "The Effects of Government Transfers on Monthly Cycles in Drug Abuse, Hospitalization and Mortality." Journal of Public Economics, 91(11-12): 21372157.

Evans, W.N., and T.J. Moore. 2011. "The Short-Term Mortality Consequences of Income Receipt." Journal of Public Economics, 95: 1410-1424.

Green, C.A., M.R. Polen, D.M. Dickinson, F.L. Lynch, and M.D. Bennett. 2002. "Gender Differences in Predictors of Initiation, Retention, and Completion in an HMO-Based Substance Abuse Treatment Program.” Journal of Substance Abuse Treatment, 23(4): 285-295.

Griffith, J.D., G.A. Rowan-Szal, R.R. Roark, and D.D. Simpson. 2000. “Contingency Management in Outpatient Methadone Treatment: a Meta-Analysis." Drug and Alcohol Dependence, 58(1-2): 55-66.

Honore, B.E., and A. Lleras-Muney. 2006. "Bounds in Competing Risks Models and the War on Cancer.” Econometrica, 74(6): 1675-1698.

Horgan, C. M., and E. L. Merrick. 2001. "Financing of Substance Abuse Treatment Services." In Alcoholism. 229-252. Springer.

Hser, Y.I., C. Teruya, A.H. Brown, D. Huang, E. Evans, and M.D. Anglin. 2007. "Impact of California's Proposition 36 on the Drug Treatment System: Treatment Capacity and Displacement." American Journal of Public Health, 97(1): 104.

Hubbard, R.L., M. E. Marsden, E. Cavanaugh, J. V. Rachal, and H. M. Ginzburg. 1988. "Role of Drug-Abuse Treatment in Limiting the Spread of AIDS." Review of Infectious Diseases, 10(2): 377-384.

Khalsa, J. H., G. Treisman, E. McCance-Katz, and E. Tedaldi. 2008. "Medical Consequences of Drug Abuse and Co-Occurring Infections: Research at the National Institute on Drug Abuse." Substance Abuse, 29(3): 5-16.

Kochanek, K.D., S.L. Murphy, J. Xu, A. Minio, and H. Kung. 2011. "Deaths: Final Data for 2009." National Vital Statistics Reports, 60(3).

Kuziemko, I., and S.D. Levitt. 2004. "An Empirical Analysis of Imprisoning Drug Offenders." Journal of Public Economics, 88(9): 2043-2066. 
Lu, M., and T.G. McGuire. 2002. "The Productivity of Outpatient Treatment for Substance Abuse." Journal of Human Resources, 309-335.

McCollister, K.E., and M.T. French. 2003. "The Relative Contribution of Outcome Domains in the Total Economic Benefit of Addiction Interventions: a Review of First Findings." Addiction, 98(12): 1647-1659.

Menninger, J.A. 2002. "Assessment and Treatment of Alcoholism and Substance-Related Disorders in the Elderly." Bulletin of the Menninger Clinic, 66(2): 166-183.

Miron, J.A. 1999. "Violence and the US Prohibitions of Drugs and Alcohol." American Law and Economics Review, 1(1): 78-114.

Moscicki, E.K. 1995. "Epidemiology of Suicidal Behavior." Suicide \& Life-Threatening Behavior, 25(1): 22-35.

Policy, Office Of National Drug Control. 2005. "FY 2005 Budget Summary.” Washington, DC: Executive Ofce of the President.

Olmstead, T., W. D. White, and J. Sindelar. 2004. "The Impact of Managed Care on Substance Abuse Treatment Services.” Health Services Research, 39(2): 319-344.

National Drug Intelligence Center (NDIC). 2011. "The Economic Impact of Illicit Drug Use on American Society.” Washington DC: United States Department of Justice.

Paulozzi, L.J., and J.L. Annest. 2007. "US Data Show Sharply Rising Drug-Induced Death Rates.” Injury Prevention, 13(2): 130-132.

Prendergast, M.L., D. Podus, E. Chang, and D. Urada. 2002. "The Effectiveness of Drug Abuse Treatment: a Meta-Analysis of Comparison Group Studies.” Drug and Alcohol Dependence, 67(1): 53-72.

Reif, S., P. George, L. Braude, R. H. Dougherty, A. S. Daniels, S. S. Ghose, and M. E. DelphinRittmon. 2014. "Residential Treatment for Individuals with Substance Use Disorders: Assessing the Evidence." Psychiatric Services.

Roy, S., and H. H. Loh. 1996. "Effects of Opioids on the Immune System." Neurochemical Research, 21(11): 1375-1386.

Ruhm, C.J. 2005. "Healthy Living in Hard Times.” Journal of health economics, 24(2): 341-363.

Ruhm, C.J. 2008. "Macroeconomic Conditions, Health and Government Policy." Making Americans Healthier: Social and Economic Policy as Health Policy: Rethinking Americas Approach to Improving Health. New York: Russel Sage Foundation 173-200.

Rydell, C.P., and S.S. Everingham. 1994. Controlling Cocaine: Supply Versus Demand Programs. Vol. 331, Rand Corp.

Sacerdote, P. 2006. “Opioids and the Immune System.” Palliative Medicine, 20(8 suppl): 9-15. 
Saffer, H., and F. Chaloupka. 1999. "The Demand for Illicit Drugs." Economic Inquiry, 37(3): 401-411.

Saffer, H., F.J. Chaloupka, and D. Dave. 2007. "State Drug Control Spending and Illicit Drug Participation.” Contemporary Economic Policy, 19(2): 150-161.

Shepard, D.S., A. Beaston-Blaakman, and C. Horgan. 2003. "The ADSS Cost Study: Costs of Substance Abuse Treatment in the Specialty Sector." Analytic Series: A-20. Rockville, MD: Substance Abuse and Mental Health Services Administration, Office of Applied Studies. DHHS Publication No. SMA 03-3762.

Solon, G., S.J. Haider, and J. Wooldridge. 2013. "What Are We Weighting For?” NBER Working Paper No. 18859.

Stevens, A.H., D.L. Miller, M.E. Page, and M. Filipski. 2011. "The Best of Times, the Worst of Times: Understanding Pro-Cyclical Mortality.” NBER Working Paper No. 17657.

Stinchcomb, J.B. 2010. "Drug courts: Conceptual Foundation, Empirical Findings, and Policy Implications.” Drugs: Education, Prevention, and Policy, 17(2): 148-167.

Substance Abuse and Mental Health Services Administration (SAMHSA), Office of Applied Studies. 2008. "National Survey of Substance Abuse Treatment Services (N-SSATS): 2007. Data on Substance Abuse Treatment Facilities." DASIS Series: S-44, DHHS Publication No. (SMA) 08-4348, Rockville, MD.

Substance Abuse and Mental Health Services Administration (SAMHSA), Office of Applied Studies. 2009. "Treatment Episode Data Set (TEDS). Highlights - 2007. National Admissions to Substance Abuse Treatment Services.” DASIS Series: S-45, DHHS Publication No. (SMA) 08-4360, Rockville, MD.

Substance Abuse and Mental Health Services Administration, Office of Applied Studies. 2011a. "Results from the 2010 National Survey on Drug Use and Health: Summary of National Findings.” NSDUH Series H-41, HHS Publication No. (SMA) 11-4658. Rockville, MD.

Substance Abuse and Mental Health Services Administration, Center for Behavioral Health Statistics and Quality. 2011b. "The N-SSATS Report: Acceptance of Private Health Insurance in Substance Abuse Treatment Facilities.” (January 6, 2011)

Tempalski, B., R. Friedman, M. Keem, H. Cooper, and S.R. Friedman. 2007. "NIMBY Localism and National Inequitable Exclusion Alliances: The Case of Syringe Exchange Programs in the United States." Geoforum, 38(6): 1250-1263.

Veilleux, J.C., P.J. Colvin, J. Anderson, C. York, and A.J. Heinz. 2010. "A Review of Opioid Dependence Treatment: Pharmacological and Psychosocial Interventions to Treat Opioid Addiction." Clinical psychology review, 30(2): 155-166.

Viscusi, W.K., and J.E. Aldy. 2003. "The Value of a Statistical Life: a Critical Review of Market Estimates throughout the World." Journal of Risk and Uncertainty, 27(1): 5-76. 
Warner, M., L.H. Chen, D.M. Makuc, R.N. Anderson, and A.M. Minio. 2011. "Drug Poisoning Deaths in the United States, 1980-2008." NCHS Data Brief. Hyattsville, MD: National Center for Health Statistics., (81). 


\section{Figure 1}

Drug-Induced Deaths

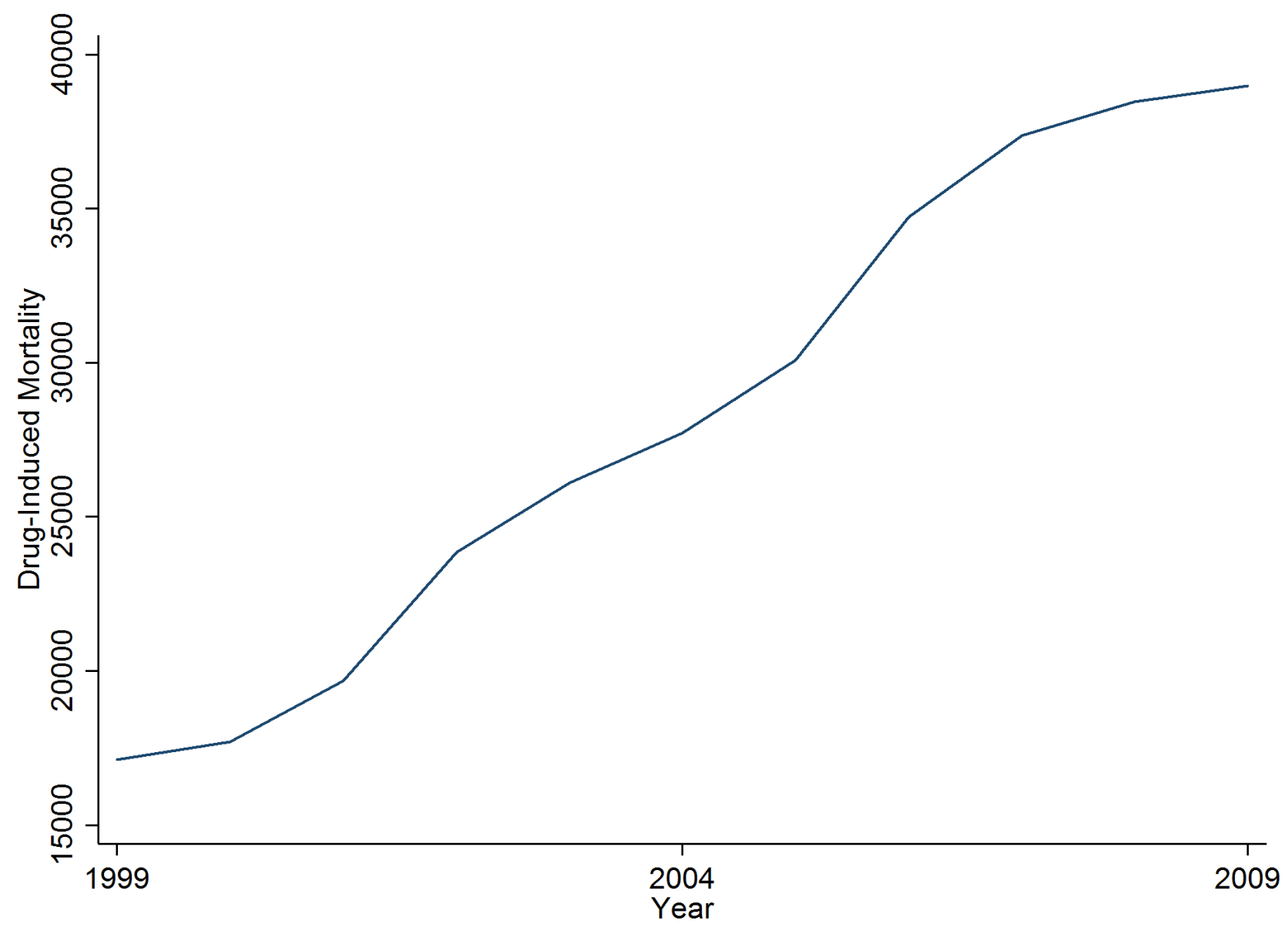

Notes: Drug-induced deaths include causes of death with specific reference to drug-induced poisoning, identified by International Classification of Diseases (ICD-10) codes. 
Figure 2

Drug-Induced Mortality following an Increase in the Number of Facilities

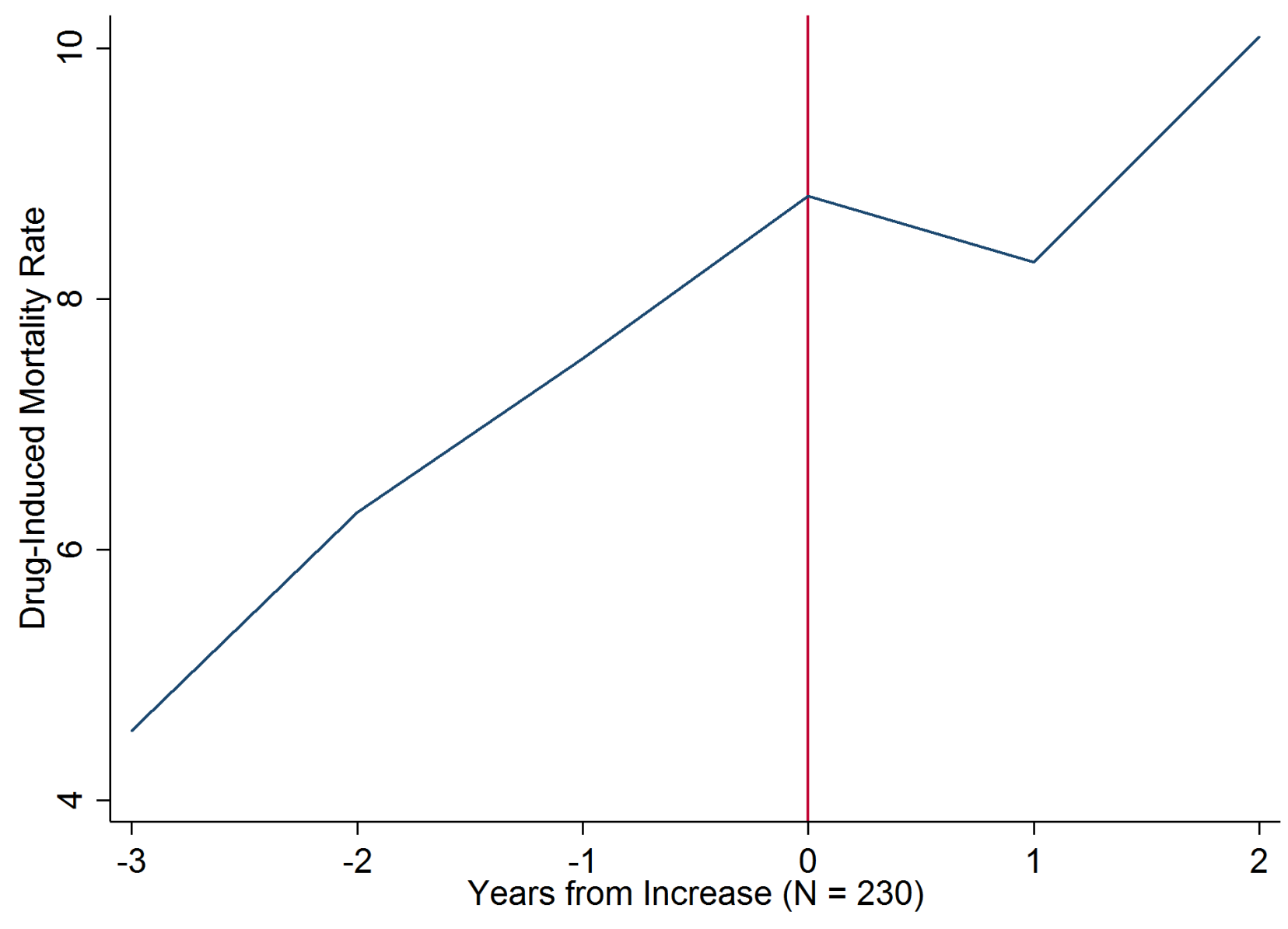

Notes: The drug-induced mortality rate is the number of drug poisonings per 100,000 residents. The figure is based on a sample of counties with a single net increase in the number of facilities over 1999-2008 and county-year observations at least 3 years leading up to and 2 years following the net increase. 
Figure 3

Drug-Induced Mortality following a Decrease in the Number of Facilities

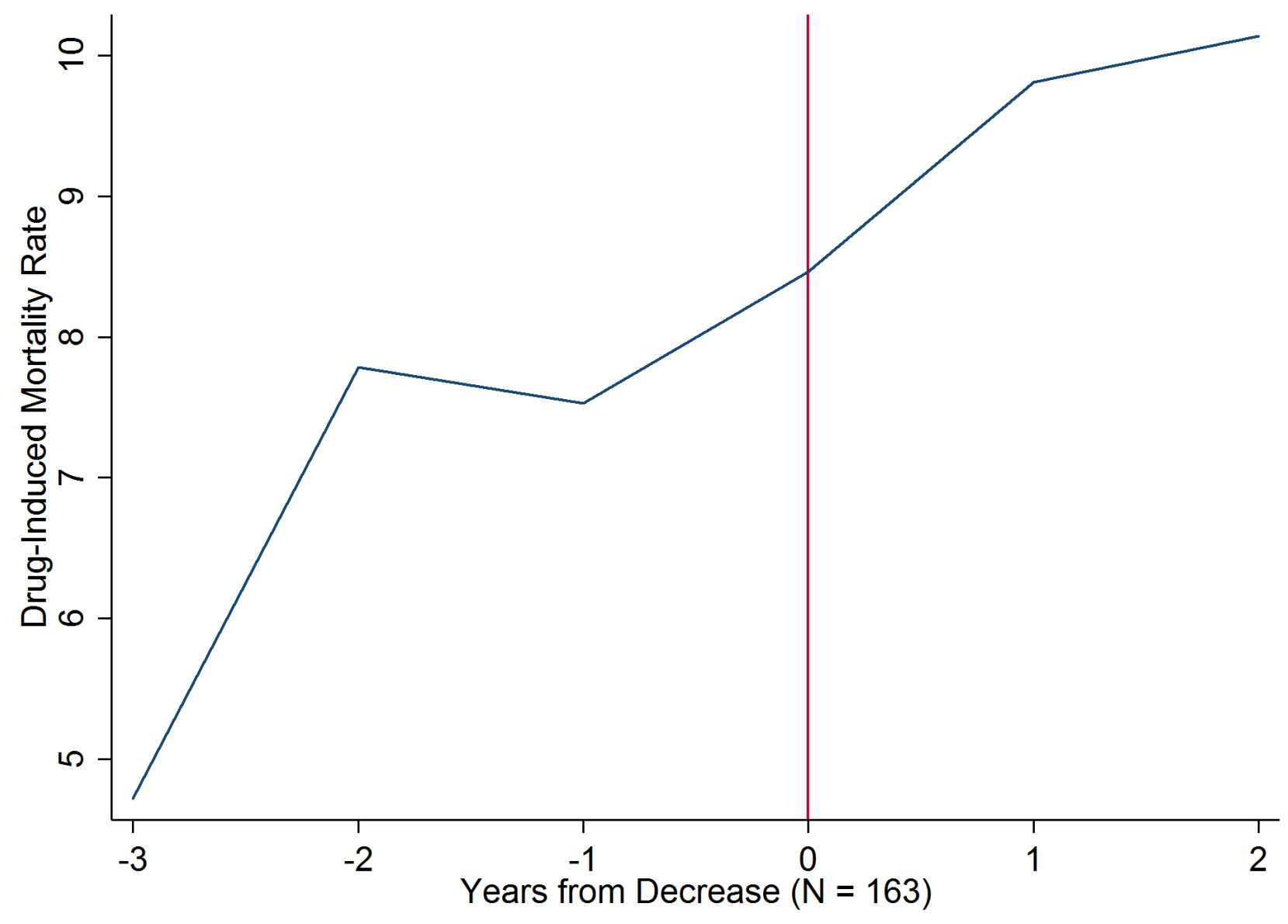

Notes: The drug-induced mortality rate is the number of drug poisonings per 100,000 residents. The figure is based on a sample of counties with a single net decrease in the number of facilities over 1999-2008 and county-year observations at least 3 years leading up to and 2 years following the net increase. 
Figure 4

Age Profiles of Drug-Induced Mortality

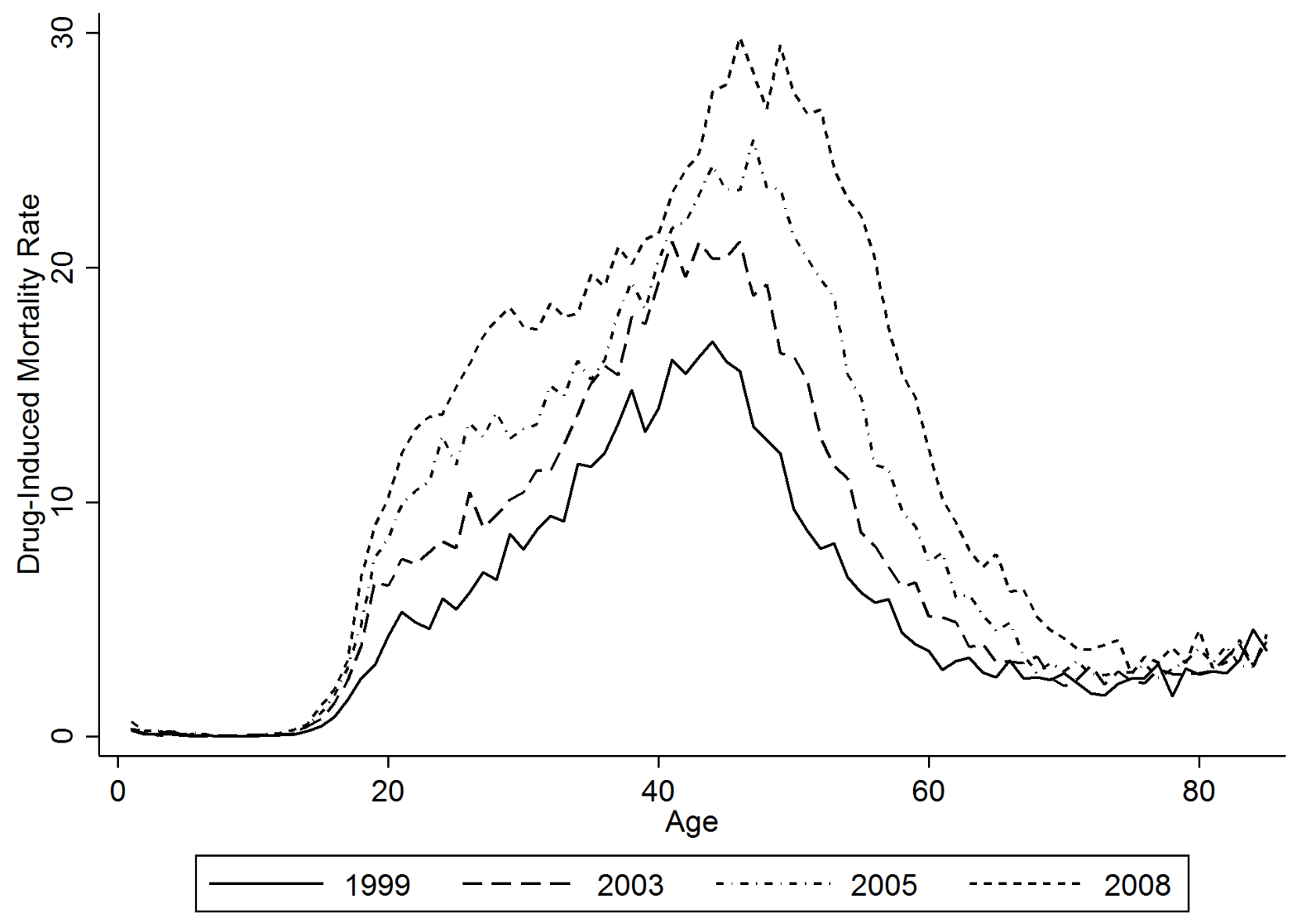

Notes: The drug-induced mortality rate is the number of drug poisonings per 100,000 residents. 


\section{Figure 5}

Estimated Effects of Treatment Facilities on Log Mortality (Ages less than 65)

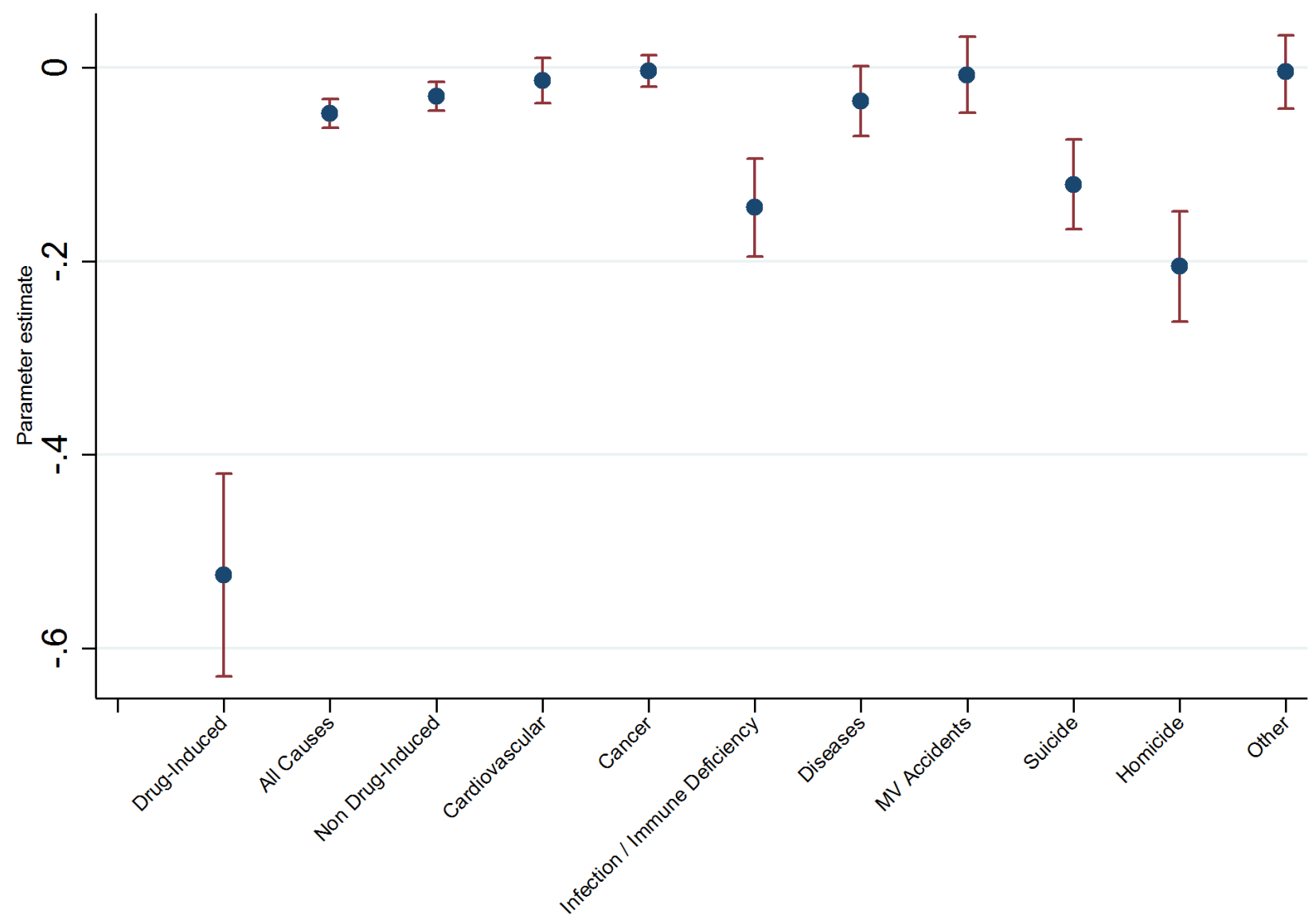

Notes: The figure summarizes the results of regressions using on logged mortality rates among individuals less than age 65 as dependent variables. The figure plots the estimated coefficients and 95\% confidence intervals associated with a change in the number of treatment facilities. Diseaserelated causes include respiratory, kidney and degenerative brain diseases. All estimates control for county-fixed effects, state-by-year fixed effects, county demographics demographic composition (fraction of the county population that are: white, black, male, less than 18 years old, 18-64 years old, and greater than 64 years old), and county-level economic conditions (the unemployment rate, firm births, and per-capita income). The estimates are weighted by county population and standard errors are corrected for possible clustering at the county level. 
Table 1

Summary Statistics

\begin{tabular}{lcc}
\hline \hline & (Mean) & (Std. Dev.) \\
\hline Substance-Abuse Treatment Facilities & & \\
Total Facilities & 47.51 & 83.41 \\
$\quad$ Net Openings & 2.23 & 6.16 \\
$\quad$ Net Closings & 1.08 & 2.9 \\
Outpatient Facilities & 25.6 & 47.43 \\
Residential Facilities & 23.06 & 39.7 \\
Facilities (per 100,000) & 4.90 & 3.52 \\
Drug-Induced Mortality (per 100,000) & & \\
All & 9.4 & 6.05 \\
Female & 6.68 & 5.14 \\
Male & 12.25 & 8.54 \\
White & 10.18 & 6.66 \\
Black & 8.02 & 29.32 \\
Other & 2.96 & 21.96 \\
Ages 0-15 & 0.18 & 0.95 \\
Ages 15-39 & 11.07 & 9.15 \\
Ages 40-64 & 16.36 & 11.59 \\
Ages 65+ & 3.29 & 4.56 \\
\hline Counties & \multicolumn{2}{c}{2,408} \\
County-Year Observations & \multicolumn{2}{c}{24,068} \\
& \multicolumn{2}{c}{} \\
\hline \hline
\end{tabular}

Notes: All statistics are weighted by county population. The sample is limited to U.S. counties within the 48 contiguous states with consistent county identifiers and at least one substance-abuse treatment facility over the sample time frame (1999-2008). 
Table 2

Estimated Effects of Treatment Facilities on Drug-Induced Mortality

\begin{tabular}{|c|c|c|c|c|}
\hline & (1) & (2) & (3) & (4) \\
\hline \multicolumn{5}{|l|}{ Panel A: All Treatment Facilities } \\
\hline Number of Facilities & $\begin{array}{c}-0.036 * * * \\
(0.006)\end{array}$ & $\begin{array}{c}-0.037 * * * \\
(0.005)\end{array}$ & $\begin{array}{c}-0.039 * * * \\
(0.005)\end{array}$ & $\begin{array}{c}-0.039 * * * \\
(0.005)\end{array}$ \\
\hline County and Year FE & yes & yes & yes & yes \\
\hline State by Year FE & no & yes & yes & yes \\
\hline Demographic Controls & no & no & yes & yes \\
\hline Controls for Economic Conditions & no & no & no & yes \\
\hline Counties & 2,408 & 2,408 & 2,408 & 2,408 \\
\hline County-Year Observations & 24,068 & 24,068 & 24,068 & 24,068 \\
\hline Mean & 9.399 & 9.399 & 9.399 & 9.399 \\
\hline$\%$ Impact & 0.387 & 0.390 & 0.417 & 0.419 \\
\hline \multicolumn{5}{|c|}{ Panel B: Facilities by Inpatient and Outpatient Setting } \\
\hline Number of Outpatient Facilities & $\begin{array}{c}-0.043 * * * \\
(0.007)\end{array}$ & $\begin{array}{c}-0.042 * * * \\
(0.007)\end{array}$ & $\begin{array}{c}-0.047 * * * \\
(0.006)\end{array}$ & $\begin{array}{c}-0.049 * * * \\
(0.006)\end{array}$ \\
\hline Number of Residential Facilities & $\begin{array}{l}-0.021 \\
(0.022)\end{array}$ & $\begin{array}{l}-0.025 \\
(0.016)\end{array}$ & $\begin{array}{c}-0.024 \\
(0.016)\end{array}$ & $\begin{array}{l}-0.020 \\
(0.015)\end{array}$ \\
\hline County and Year FE & yes & yes & yes & yes \\
\hline State by Year FE & no & yes & yes & yes \\
\hline Demographic Controls & no & no & yes & yes \\
\hline Controls for Economic Conditions & no & no & no & yes \\
\hline Counties & 2,408 & 2,408 & 2,408 & 2,408 \\
\hline County-Year Observations & 24,068 & 24,068 & 24,068 & 24,068 \\
\hline Mean & 9.399 & 9.399 & 9.399 & 9.399 \\
\hline
\end{tabular}

Notes: The dependent variable is a county's annual drug-induced mortality rate per 100,000 residents. Demographic controls include the fraction of the county population that are: white, black, male, less than 18 years old, 18-64 years old, and greater than 64 years old. Controls for economic conditions include the unemployment rate, firm births, and per-capita income. Number of Facilities is the count of treatment facilities in a county by year. The estimates are weighted by county population and standard errors (in parentheses) are corrected for possible clustering at the county level.

* significant at $10 \%$;* significant at $5 \% ; * * *$ significant at $1 \%$ 
Table 3

Estimated effect of Facilities on Drug-Induced Mortality using Lags and Leads

\begin{tabular}{|c|c|c|c|c|}
\hline & (1) & (2) & (3) & (4) \\
\hline Number of Facilities $t_{t-2}$ & & $\begin{array}{c}-0.022 * * * \\
(0.006)\end{array}$ & & \\
\hline Number of Facilities ${ }_{t-1}$ & $\begin{array}{c}-0.039 * * * \\
(0.005)\end{array}$ & $\begin{array}{c}-0.022 * * * \\
(0.006)\end{array}$ & $\begin{array}{c}-0.026 * * * \\
(0.006)\end{array}$ & $\begin{array}{c}-0.026 * * * \\
(0.006)\end{array}$ \\
\hline Number of Facilities $_{t}$ & & & $\begin{array}{c}-0.016 * * \\
(0.007)\end{array}$ & $\begin{array}{l}-0.010 \\
(0.007)\end{array}$ \\
\hline Number of Facilities $_{t+1}$ & & & & $\begin{array}{l}-0.000 \\
(0.009)\end{array}$ \\
\hline Counties & 2,408 & 2,408 & 2,408 & 2,408 \\
\hline County-Year Observations & 24,068 & 21,660 & 24,068 & 21,660 \\
\hline
\end{tabular}

Notes: The dependent variable is a county's annual drug-induced mortality rate per 100,000 residents. The regressions include county fixed effects, state-by-year fixed effects and county-level controls for the unemployment rate, firm births, per-capita income, and the fraction of the county population that are: white, black, male, less than 18 years old, 18-64 years old, and greater than 64 years old. Number of Facilities is the count of treatment facilities in a county by year. The estimates are weighted by county population and standard errors (in parentheses) are corrected for possible clustering at the county level.

* significant at $10 \% ; * *$ significant at $5 \% ; * * *$ significant at $1 \%$ 
Table 4

Heterogeneity in the Effect of Treatment Facilities on Drug-Induced Mortality by Age

\begin{tabular}{|c|c|c|c|c|c|c|c|c|c|}
\hline & \multirow{3}{*}{ All Ages } & (2) & (3) & (4) & (5) & (6) & (7) & (8) & (9) \\
\hline & & \multicolumn{8}{|c|}{ Age-adjusted Mortality Rates } \\
\hline & & $<10$ & $10-19$ & $20-29$ & $30-39$ & $40-49$ & $50-59$ & $60-69$ & $70+$ \\
\hline Number of Facilities & $\begin{array}{c}-0.039 * * * * \\
(0.005)\end{array}$ & $\begin{array}{l}-0.000 \\
(0.000)\end{array}$ & $\begin{array}{c}-0.007 * * * * \\
(0.003)\end{array}$ & $\begin{array}{c}-0.043 * * * \\
(0.007)\end{array}$ & $\begin{array}{c}-0.073 * * * \\
(0.010)\end{array}$ & $\begin{array}{c}-0.077 * * * \\
(0.013)\end{array}$ & $\begin{array}{c}-0.067 * * * \\
(0.016)\end{array}$ & $\begin{array}{c}-0.027 * * * * \\
(0.009)\end{array}$ & $\begin{array}{c}-0.018 * * * \\
(0.004)\end{array}$ \\
\hline Counties & 2,408 & 2,408 & 2,408 & 2,408 & 2,408 & 2,408 & 2,408 & 2,408 & 2,408 \\
\hline County-Year Observations & 24,068 & 24,068 & 24,068 & 24,068 & 24,068 & 24,068 & 24,068 & 24,068 & 24,068 \\
\hline Mean & 9.399 & 0.171 & 1.811 & 10.83 & 15.36 & 21.42 & 13.89 & 4.925 & 3.122 \\
\hline$\%$ Impact & 0.419 & 0.126 & 0.407 & 0.398 & 0.475 & 0.358 & 0.482 & 0.557 & 0.561 \\
\hline
\end{tabular}

Notes: The dependent variables are a county's annual age-adjusted drug-induced mortality rate per 100,000 residents. The regressions include county fixed effects, state-by-year fixed effects and county-level controls for the unemployment rate, firm births, per-capita income, and the fraction of the county population that are: white, black, male, less than 18 years old, 18-64 years old, and greater than 64 years old. Number of Facilities is the count of treatment facilities in a county by year. The estimates are weighted by county population and standard errors (in parentheses) are corrected for possible clustering at the county level.

$*$ significant at $10 \% ; * *$ significant at $5 \% ; * * *$ significant at $1 \%$ 
Table 5

Heterogeneity in the Effect of Treatment Facilities Across Race and Gender

\begin{tabular}{lcccccc}
\hline \hline & $(1)$ & $(2)$ & $(3)$ & $(4)$ & $(5)$ & $(6)$ \\
& All & blacks & whites & other & male & female \\
\hline Number of Facilities & $-0.039^{* * *}$ & $-0.039 * * *$ & $-0.040^{* * *}$ & $-0.012^{* *}$ & $-0.051^{* * *}$ & $-0.028^{* * *}$ \\
& $(0.005)$ & $(0.014)$ & $(0.006)$ & $(0.005)$ & $(0.007)$ & $(0.004)$ \\
Counties & & & & & & \\
County-Year Observations & 2,408 & 2,406 & 2,408 & 2,408 & 2,408 & 2,408 \\
Mean & 24,068 & 23,981 & 24,068 & 24,057 & 24,068 & 24,068 \\
\% Impact & 9.399 & 8.019 & 10.18 & 2.961 & 12.25 & 6.679 \\
\hline \hline
\end{tabular}

Notes: The dependent variables are a county's annual demographic-specific drug-induced mortality rate per 100,000 residents corresponding to each column heading. The regressions include county fixed effects, stateby-year fixed effects and county-level controls for the unemployment rate, firm births, per-capita income, and the fraction of the county population that are: white, black, male, less than 18 years old, 18-64 years old, and greater than 64 years old. Number of Facilities is the count of treatment facilities in a county by year. The estimates are weighted by county population and standard errors (in parentheses) are corrected for possible clustering at the county level.

* significant at $10 \%$; * significant at $5 \% ; * * *$ significant at $1 \%$ 
Table 6

Heterogeneity in the Effect of Treatment Facilities Across County Characteristics

\begin{tabular}{|c|c|c|c|c|c|c|c|}
\hline & (1) & \multicolumn{3}{|c|}{ Urban Classification } & \multicolumn{3}{|c|}{ Income } \\
\hline & & Large Urban & Med/Small Urban & Rural & Low & Med & High \\
\hline Number of Facilities & $\begin{array}{c}-0.039 * * * \\
(0.005)\end{array}$ & $\begin{array}{c}-0.039 * * * \\
(0.010)\end{array}$ & $\begin{array}{c}-0.029 * * * \\
(0.011)\end{array}$ & $\begin{array}{c}0.019 \\
(0.051)\end{array}$ & $\begin{array}{l}-0.091 \\
(0.060)\end{array}$ & $\begin{array}{c}-0.055^{* *} \\
(0.025)\end{array}$ & $\begin{array}{c}-0.041 * * * \\
(0.005)\end{array}$ \\
\hline $\begin{array}{l}\text { Counties } \\
\text { County-Year Observations }\end{array}$ & $\begin{array}{c}2,408 \\
24,068\end{array}$ & $\begin{array}{c}61 \\
610\end{array}$ & $\begin{array}{c}916 \\
9,148\end{array}$ & $\begin{array}{c}1,431 \\
14,310\end{array}$ & $\begin{array}{c}802 \\
8,020\end{array}$ & $\begin{array}{c}802 \\
8,016\end{array}$ & $\begin{array}{c}803 \\
8,022\end{array}$ \\
\hline $\begin{array}{l}\text { Mean } \\
\% \text { Impact }\end{array}$ & $\begin{array}{l}9.399 \\
0.419\end{array}$ & $\begin{array}{l}10.39 \\
0.375\end{array}$ & $\begin{array}{l}9.022 \\
0.321\end{array}$ & $\begin{array}{l}8.788 \\
0.220\end{array}$ & $\begin{array}{l}9.332 \\
0.971\end{array}$ & $\begin{array}{l}9.065 \\
0.609\end{array}$ & $\begin{array}{l}9.499 \\
0.436\end{array}$ \\
\hline
\end{tabular}

Notes: The dependent variable is a county's annual drug-induced mortality rate per 100,000 residents. The regressions include county fixed effects, state-by-year fixed effects and county-level controls for the unemployment rate, firm births, per-capita income, and the fraction of the county population that are: white, black, male, less than 18 years old, 18-64 years old, and greater than 64 years old. Number of Facilities is the count of treatment facilities in a county by year. The estimates are weighted by county population and standard errors (in parentheses) are corrected for possible clustering at the county level.

$*$ significant at $10 \% ; * *$ significant at $5 \% ; * * *$ significant at $1 \%$ 
Table 7

Estimated Correlations Between Covariates and the Number of Facilities

\begin{tabular}{|c|c|c|c|c|c|}
\hline & $\begin{array}{c}\text { (1) } \\
\text { Demographics }\end{array}$ & $\begin{array}{l}(2) \\
\text { Economy }\end{array}$ & $\begin{array}{c}(3) \\
\text { Crime }\end{array}$ & $\begin{array}{c}(4) \\
\text { Law Enforcement }\end{array}$ & $\begin{array}{l}(5) \\
\text { All }\end{array}$ \\
\hline County Population P $_{t-1}$ & $\begin{array}{c}0.094 * * \\
(0.048)\end{array}$ & & & & $\begin{array}{c}0.045 \\
(0.035)\end{array}$ \\
\hline Percent Ages $10-19_{t-1}$ & $\begin{array}{l}6.848 * \\
(3.982)\end{array}$ & & & & $\begin{array}{l}4.833^{*} \\
(2.700)\end{array}$ \\
\hline Percent Ages $20-29_{t-1}$ & $\begin{array}{l}8.412 * * \\
(3.693)\end{array}$ & & & & $\begin{array}{l}6.584 * * \\
(2.569)\end{array}$ \\
\hline Percent Ages $40-64_{t-1}$ & $\begin{array}{c}4.479 \\
(2.821)\end{array}$ & & & & $\begin{array}{c}3.091 \\
(1.916)\end{array}$ \\
\hline Percent Ages $65+_{t-1}$ & $\begin{array}{l}7.972 * \\
(4.269)\end{array}$ & & & & $\begin{array}{l}6.133 * * \\
(2.950)\end{array}$ \\
\hline Percent Other NonWhite ${ }_{t-1}$ & $\begin{array}{l}-1.732 \\
(2.737)\end{array}$ & & & & $\begin{array}{l}-1.434 \\
(1.944)\end{array}$ \\
\hline Percent Black $t-1$ & $\begin{array}{c}-1.890 * * \\
(0.960)\end{array}$ & & & & $\begin{array}{l}-1.067 \\
(0.649)\end{array}$ \\
\hline Percent Male $_{t-1}$ & $\begin{array}{l}-5.185 * * * \\
(1.675)\end{array}$ & & & & $\begin{array}{c}-3.815^{* * * *} \\
(1.393)\end{array}$ \\
\hline Unemployment Rate R $_{t-1}$ & & $\begin{array}{l}-1.113^{*} \\
(0.579)\end{array}$ & & & $\begin{array}{l}-0.921 * \\
(0.503)\end{array}$ \\
\hline New Firm Births $s_{t-1}$ & & $\begin{array}{c}0.015 * * * \\
(0.003)\end{array}$ & & & $\begin{array}{c}0.012 * * * \\
(0.001)\end{array}$ \\
\hline Per Capita Income In-1 $_{1}$ & & $\begin{array}{c}0.000 \\
(0.000)\end{array}$ & & & $\begin{array}{l}0.000^{*} \\
(0.000)\end{array}$ \\
\hline $\mathrm{DUI}_{t-1}$ & & & $\begin{array}{c}0.001 \\
(0.003)\end{array}$ & & $\begin{array}{c}0.001 \\
(0.002)\end{array}$ \\
\hline Disorderly Conduct Co $_{t-1}$ & & & $\begin{array}{l}-0.001 \\
(0.002)\end{array}$ & & $\begin{array}{l}-0.001 \\
(0.001)\end{array}$ \\
\hline Drug Possession $_{t-1}$ & & & $\begin{array}{l}-0.000 \\
(0.002)\end{array}$ & & $\begin{array}{l}-0.001 \\
(0.002)\end{array}$ \\
\hline Law Enforcement $t_{t-1}$ & & & & $\begin{array}{l}-0.005 \\
(0.009)\end{array}$ & $\begin{array}{l}-0.007 \\
(0.005)\end{array}$ \\
\hline County FE & yes & yes & yes & yes & yes \\
\hline State by Year FE & yes & yes & yes & yes & yes \\
\hline F Statistic & 2.037 & 17.18 & 0.0950 & 0.320 & 22.93 \\
\hline $\begin{array}{l}\text { Counties } \\
\text { County-Year Observations }\end{array}$ & $\begin{array}{c}2,408 \\
24,068\end{array}$ & $\begin{array}{c}2,408 \\
24,068\end{array}$ & $\begin{array}{c}2,408 \\
24,068\end{array}$ & $\begin{array}{c}2,408 \\
24,068\end{array}$ & $\begin{array}{c}2,408 \\
24,068\end{array}$ \\
\hline
\end{tabular}

Notes: The dependent variable is a county's number of substance-abuse treatment facilities. Population counts are measured in 1000s. The estimates are weighted by county population and standard errors (in parentheses) are corrected for possible clustering at the county level.

* significant at $10 \% ; * *$ significant at $5 \% ; * * *$ significant at $1 \%$ 
Table 8

Summary Statistics (N-SSATS Data)

\begin{tabular}{|c|c|c|c|c|}
\hline & \multicolumn{2}{|c|}{ Full Sample } & \multicolumn{2}{|c|}{ TEDS Analysis } \\
\hline & (Mean) & (Std. Dev.) & (Mean) & (Std. Dev.) \\
\hline \multicolumn{5}{|c|}{ Substance-Abuse Treatment Facilities } \\
\hline Total Facilities & 27.43 & 50.33 & 30.53 & 53.28 \\
\hline Openings & 3.2 & 7.53 & 3.63 & 8.04 \\
\hline Closings & 1.8 & 3.43 & 2.04 & 3.64 \\
\hline Private, Non-Profit Facilities & 16.17 & 33.71 & 18.19 & 35.85 \\
\hline Private, For-Profit Facilities & 9.76 & 16.51 & 10.65 & 17.32 \\
\hline Public Facilities & 1.51 & 2.64 & 1.69 & 2.79 \\
\hline Residential Facilities & 22.8 & 42 & 5.1 & 9.7 \\
\hline Outpatient Facilities & 4.63 & 9.18 & 25.43 & 44.5 \\
\hline Funded Facilities & 18.31 & 34.68 & 20.24 & 36.77 \\
\hline Unfunded Facilities & 8.52 & 14.87 & 9.47 & 15.72 \\
\hline \multicolumn{5}{|c|}{ Substance-Abuse Treatment Admissions (per 100,000) } \\
\hline Total Admissions & - & - & 679.06 & 657.05 \\
\hline Outpatient Admissions & - & - & 439.05 & 419.2 \\
\hline Inpatient Admissions & - & - & 240.01 & 389.01 \\
\hline \multicolumn{5}{|c|}{ Drug-Induced Mortality (per 100,000) } \\
\hline All & 10.67 & 6.13 & 30.52 & 53.28 \\
\hline Female & 7.72 & 5.29 & 7.67 & 4.98 \\
\hline Male & 13.76 & 8.6 & 13.9 & 8.2 \\
\hline White & 11.61 & 6.76 & 11.68 & 6.57 \\
\hline Black & 8.7 & 19.58 & 8.9 & 17.46 \\
\hline Other & 3.4 & 22.51 & 3.2 & 18.84 \\
\hline Ages 0-15 & 0.2 & 0.96 & 0.19 & 0.84 \\
\hline Ages 15-39 & 12.44 & 9.54 & 12.35 & 9.01 \\
\hline Ages 40-64 & 18.67 & 11.76 & 18.89 & 11.37 \\
\hline Ages $65+$ & 3.59 & 4.53 & 3.6 & 4.11 \\
\hline Counties & \multicolumn{2}{|c|}{2,113} & \multicolumn{2}{|c|}{1,578} \\
\hline County-Year Observations & \multicolumn{2}{|c|}{14,791} & \multicolumn{2}{|c|}{9,511} \\
\hline
\end{tabular}

Notes: All statistics are weighted by county population. The samples are limited to U.S. counties within the 48 contiguous states with consistent county identifiers and at least one substance-abuse treatment facility over the sample time frame (2002-2008). The samples are limited to non-hospital facilities that are licensed, certified, or accredited to provide substance-abuse treatment. The sample in Column (2) is further restricted to counties reporting treatment admissions in states that require publicly-funded facilities to report substance-abuse treatment admissions. 
Table 9

Estimated Effects of Treatment Facilities on Mortality Using N-SSATS Data

\begin{tabular}{|c|c|c|c|c|}
\hline & (1) & $(2)$ & (3) & (4) \\
\hline \multicolumn{5}{|c|}{ Panel A: Estimates by the change in number of facilities } \\
\hline Number of Facilities & $\begin{array}{c}-0.048 * * * \\
(0.018)\end{array}$ & $\begin{array}{c}-0.039 * * * \\
(0.011)\end{array}$ & $\begin{array}{c}-0.045 * * * \\
(0.012)\end{array}$ & $\begin{array}{c}-0.042 * * * \\
(0.013)\end{array}$ \\
\hline County and Year FE & yes & yes & yes & yes \\
\hline State by Year FE & no & yes & yes & yes \\
\hline Demographic Controls & no & no & yes & yes \\
\hline Controls for Economic Conditions & no & no & no & yes \\
\hline Counties & 2,113 & 2,113 & 2,113 & 2,113 \\
\hline County-Year Observations & 14,791 & 14,791 & 14,791 & 14,791 \\
\hline Mean & 10.67 & 10.67 & 10.67 & 10.67 \\
\hline$\%$ Impact & 0.447 & 0.365 & 0.421 & 0.395 \\
\hline \multicolumn{5}{|c|}{ Panel B: Estimates separately for Openings and Closings } \\
\hline Facility Opening & $\begin{array}{c}-0.030 * * \\
(0.013)\end{array}$ & $\begin{array}{c}-0.025 * * \\
(0.012)\end{array}$ & $\begin{array}{c}-0.028 * * \\
(0.012)\end{array}$ & $\begin{array}{c}-0.029 * * \\
(0.012)\end{array}$ \\
\hline Facility Closing & $\begin{array}{l}-0.007 \\
(0.027)\end{array}$ & $\begin{array}{c}0.009 \\
(0.025)\end{array}$ & $\begin{array}{c}0.011 \\
(0.026)\end{array}$ & $\begin{array}{c}0.012 \\
(0.027)\end{array}$ \\
\hline County and Year FE & yes & yes & yes & yes \\
\hline State by Year FE & no & yes & yes & yes \\
\hline Demographic Controls & no & no & yes & yes \\
\hline Controls for Economic Conditions & no & no & no & yes \\
\hline Counties & 2,113 & 2,113 & 2,113 & 2,113 \\
\hline County-Year Observations & 12,678 & 12,678 & 12,678 & 12,678 \\
\hline
\end{tabular}

Notes: The dependent variable is a county's annual drug-induced mortality rate per 100,000 residents. Demographic controls include the fraction of the county population that are: white, black, male, less than 18 years old, 18-64 years old, and greater than 64 years old. Controls for economic conditions include the unemployment rate, firm births, and per-capita income. Number of Facilities is the count of treatment facilities in a county by year. The estimates are weighted by county population and standard errors (in parentheses) are corrected for possible clustering at the county level.

$*$ significant at $10 \%$;* significant at $5 \%$; *** significant at $1 \%$ 
Table 10

Estimated Effects of Treatment facilities by Facility Type

\begin{tabular}{|c|c|c|c|c|}
\hline & $\begin{array}{c}(1) \\
\text { Treatment Setting }\end{array}$ & $\begin{array}{c}\text { (2) } \\
\text { Ownership Type }\end{array}$ & $\begin{array}{c}\text { (3) } \\
\text { Facility Size }\end{array}$ & $\begin{array}{c}(4) \\
\text { Funding Status }\end{array}$ \\
\hline Outpatient Facilities & $\begin{array}{c}-0.053 * * * \\
(0.016)\end{array}$ & & & \\
\hline Inpatient Facilities & $\begin{array}{l}-0.010 \\
(0.028)\end{array}$ & & & \\
\hline Private, Non-Profit Facilities & & $\begin{array}{c}-0.063 * * * \\
(0.023)\end{array}$ & & \\
\hline Private, For-Profit Facilities & & $\begin{array}{l}-0.020 \\
(0.024)\end{array}$ & & \\
\hline Public Facilities & & $\begin{array}{l}-0.245^{*} \\
(0.145)\end{array}$ & & \\
\hline Small Facilities & & & $\begin{array}{l}-0.026 \\
(0.036)\end{array}$ & \\
\hline Medium Facilities & & & $\begin{array}{c}-0.042 * \\
(0.023)\end{array}$ & \\
\hline Large Facilities & & & $\begin{array}{c}-0.049 \\
(0.056)\end{array}$ & \\
\hline Funded Facilities & & & & $\begin{array}{c}-0.080 * * * \\
(0.018)\end{array}$ \\
\hline Unfunded Facilities & & & & $\begin{array}{c}0.009 \\
(0.021)\end{array}$ \\
\hline Counties & 2,113 & 2,113 & 2,113 & 2,113 \\
\hline County-Year Observations & 14,791 & 14,791 & 14,791 & 14,791 \\
\hline
\end{tabular}

Notes: The dependent variable is a county's annual drug-induced mortality rate per 100,000 residents. The regressions include county fixed effects, state-by-year fixed effects and county-level controls for the unemployment rate, firm births, per-capita income, and the fraction of the county population that are: white, black, male, less than 18 years old, 18-64 years old, and greater than 64 years old. Number of Facilities is the count of treatment facilities in a county by year. The estimates are weighted by county population and standard errors (in parentheses) are corrected for possible clustering at the county level.

* significant at $10 \%$;* significant at $5 \% ; * * *$ significant at $1 \%$ 
Table 11

Estimated Effects of Treatment Facilities on Admissions Using N-SSATS Data

\begin{tabular}{lccc}
\hline \hline & $(1)$ & $(2)$ & $(3)$ \\
& Total Admissions & Outpatient Admissions & Inpatient Admissions \\
\hline Publicly-Funded Facilities & $2.011^{*}$ & $2.810^{* *}$ & -0.799 \\
& $(1.201)$ & $(1.130)$ & $(0.705)$ \\
Unfunded Facilities & 0.289 & 0.241 & 0.048 \\
& $(1.016)$ & $(0.648)$ & $(0.619)$ \\
Counties & & & \\
County-Year Observations & 1,578 & 1,578 & 1,578 \\
\hline \hline
\end{tabular}

Notes: The dependent variable is a county's annual number of substance-abuse treatment admissions (per 100,000 residents) into publicly-funded facilities. The regressions include county fixed effects, state-byyear fixed effects and county-level controls for the unemployment rate, firm births, per-capita income, and the fraction of the county population that are: white, black, male, less than 18 years old, 18-64 years old, and greater than 64 years old. Number of Facilities is the count of treatment facilities in a county by year. The estimates are weighted by county population and standard errors (in parentheses) are corrected for possible clustering at the county level.

* significant at $10 \%$; * significant at $5 \% ; * * *$ significant at $1 \%$ 


\section{Appendix}

Figure A1

Drug-Induced Mortality by Race and Gender
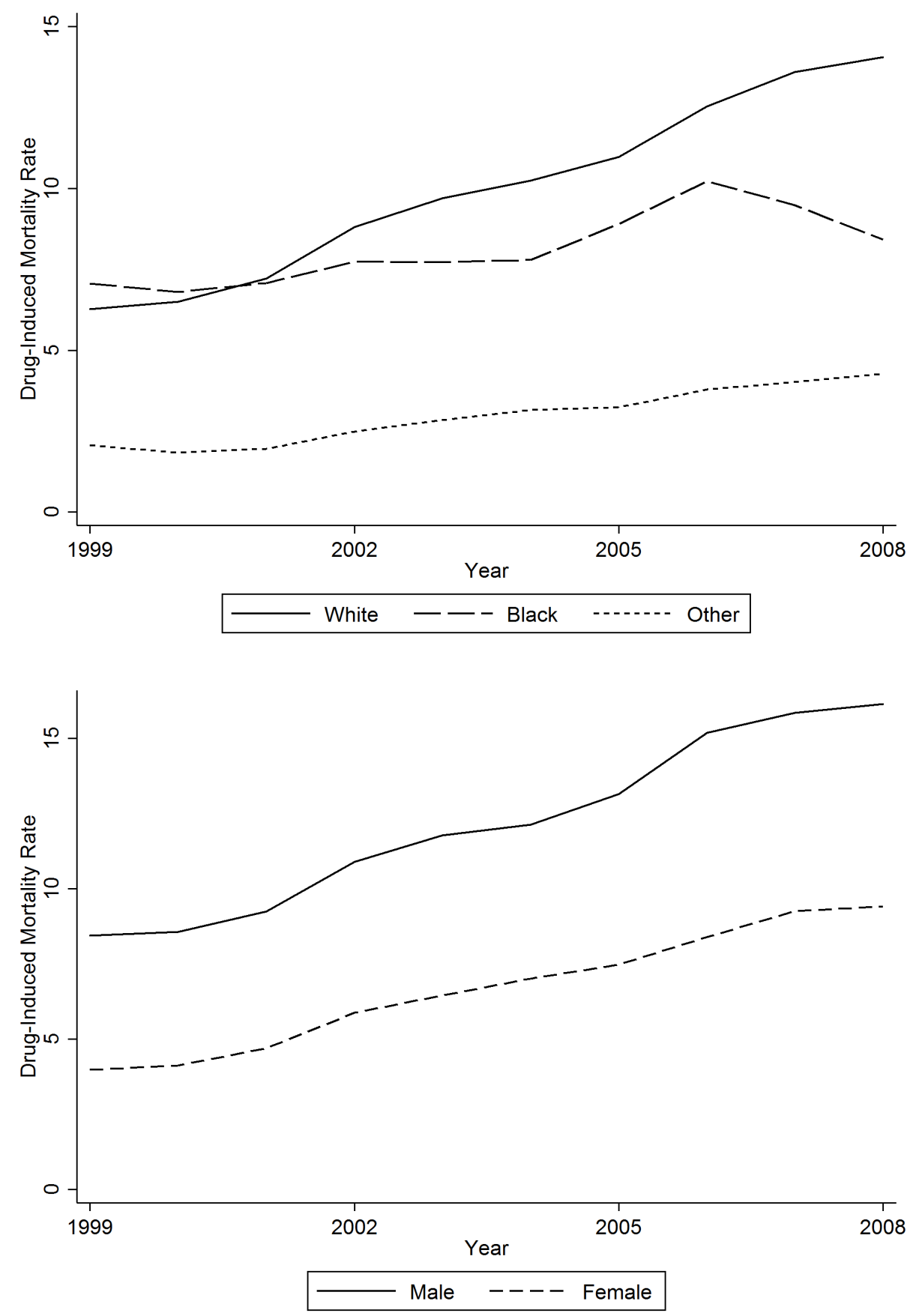

Notes: The drug-induced mortality rate is the number of drug poisonings per 100,000 residents. 
Figure A2

Drug-Induced Mortality by Urban Classification

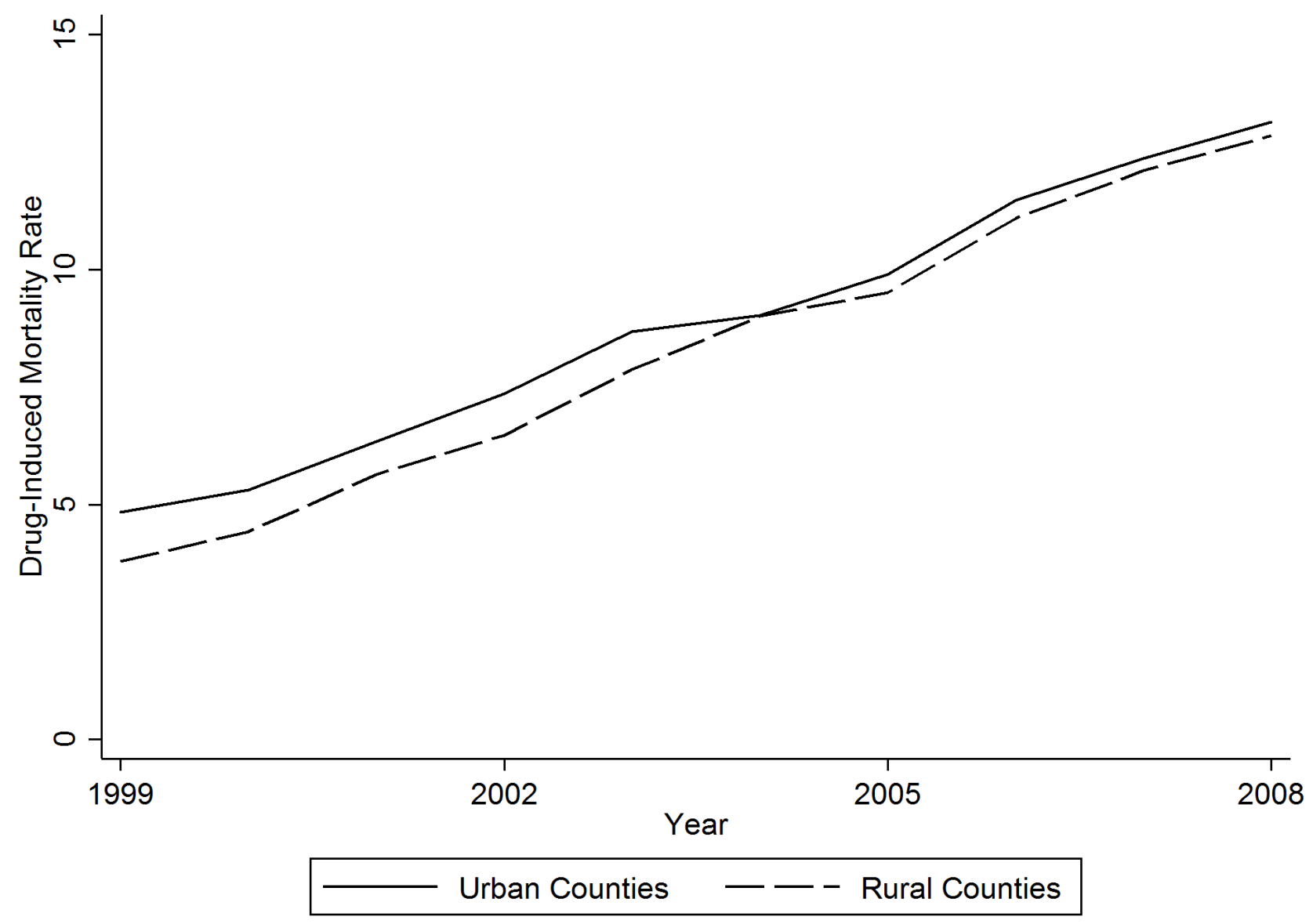

Notes: The drug-induced mortality rate is the number of drug poisonings per 100,000 residents. Urban and Rural categories are based on the National Center for Heath Statistics (NCHS) urbanrural classification scheme for counties. Counties within a metropolitan statistical area (MSA) are classified as urban while non-MSA counties are classified as rural. 
Figure A3

Estimated Effects of Treatment Facilities on Log Mortality (All Ages)

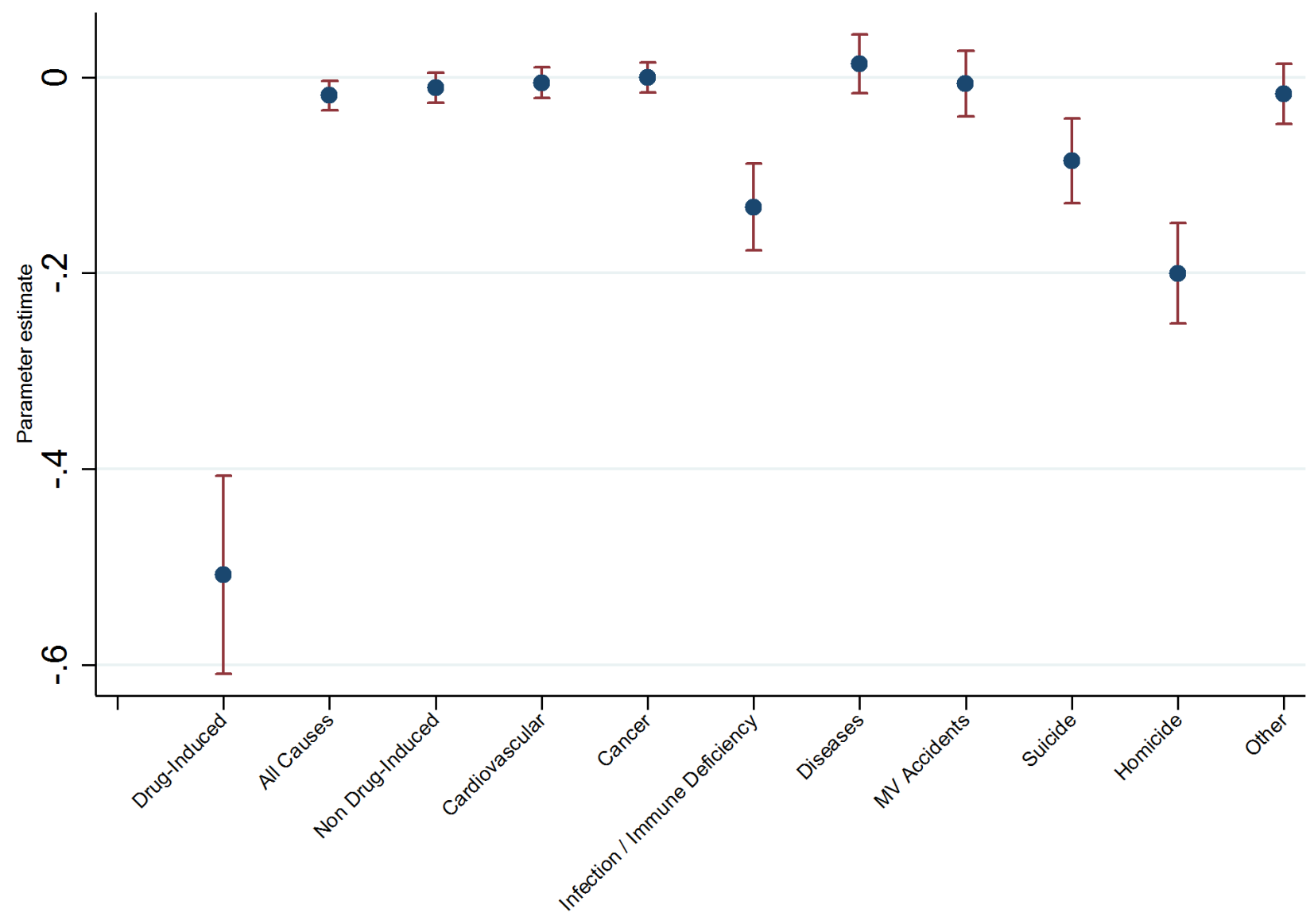

Notes: The figure summarizes the results of regressions using on logged mortality rates as dependent variables. The figure plots the estimated coefficients and $95 \%$ confidence intervals associated with a change in the number of treatment facilities. Disease-related causes include respiratory, kidney and degenerative brain diseases. All estimates control for county-fixed effects, state-by-year fixed effects, county demographics demographic composition (fraction of the county population that are: white, black, male, less than 18 years old, 18-64 years old, and greater than 64 years old), and county-level economic conditions (the unemployment rate, firm births, and per-capita income). The estimates are weighted by county population and standard errors are corrected for possible clustering at the county level. 
Figure A4

Comparison of N-SSATS and CBP Facility Counts

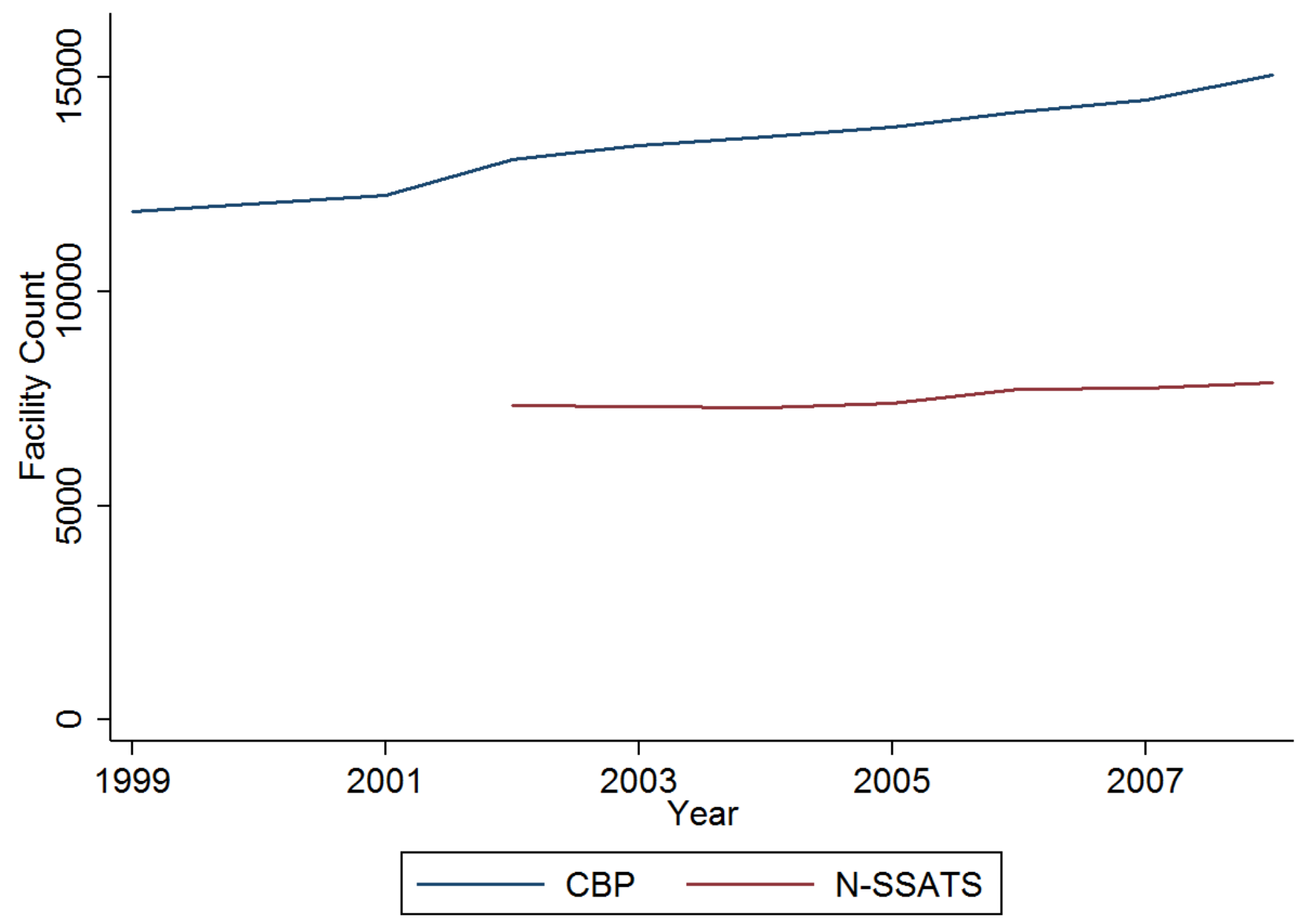

Notes:Facility count is the total number of facilities reported by each data source. 
Table A1

Estimated Effects of Treatment Facilities on Drug-Induced Mortality Inclusive of All Covariates

\begin{tabular}{lccc}
\hline \hline & $(1)$ & $(2)$ & $(3)$ \\
\hline Number of Facilities & $-0.037 * * *$ & $-0.039 * * *$ & $-0.039 * * *$ \\
& $(0.005)$ & $(0.005)$ & $(0.005)$ \\
Percent Ages 18-64 & & $0.438^{* * *}$ & $0.436 * * *$ \\
& & $(0.157)$ & $(0.155)$ \\
Percent Ages 65+ & 0.220 & 0.229 \\
& & $(0.214)$ & $(0.215)$ \\
Percent Black & 0.135 & 0.116 \\
& $(0.110)$ & $(0.111)$ \\
Percent Other Non-White & & $-0.574 * * *$ & $-0.575 * * *$ \\
& & $(0.147)$ & $(0.150)$ \\
Percent Male & & 0.131 & 0.120 \\
& & $(0.288)$ & $(0.288)$ \\
New Firm Births & & & 0.000 \\
& & & $(0.000)$ \\
Unemployment Rate & & & 0.080 \\
& & & $-0.078)$ \\
Per Capita Income & & & $(0.000)$ \\
& & 2,408 & 2,408 \\
Counties & & 24,068 & 24,068 \\
County-Year Observations & 24,068 & & \\
\hline \hline
\end{tabular}

Notes: The dependent variable is a county's annual number of drug-induced deaths. The regressions include county fixed effects and state-by-year fixed effects. Number of Facilities is the count of treatment facilities in a county by year. The estimates are weighted by county population and standard errors (in parentheses) are corrected for possible clustering at the county level.

* significant at $10 \%$; * significant at $5 \%$; *** significant at $1 \%$ 
Table A2

Classification of Cause of Death

\begin{tabular}{ll}
\hline \hline Death Category & ICD-10 \\
\hline Drug-Induced Mortality & $\mathrm{X} 40-\mathrm{X} 45, \mathrm{X} 60-\mathrm{X} 65, \mathrm{X} 85, \mathrm{Y} 10-\mathrm{Y} 15$ \\
\hline Cardiovascular & 113 Category Recode: $53-75$ \\
\hline Cancer & 113 Category Recode: $19-44$ \\
\hline Infection / Immune Deficiency & $\mathrm{N} 390, \mathrm{D} 849$ \\
& $113 \quad$ Category Recode: $1-18$, \\
\hline Disease & R092, F03, F019, F069 F79, F179, F109, F329, \\
& G35, G122, G319, G409, G419, G459, G700, G809, $919, \mathrm{G} 931, \mathrm{G} 934, \mathrm{M} 349, \mathrm{R} 54, \mathrm{R} 628, \mathrm{~N} 289$ \\
& 113 Category Recode: $76-89,51,52,98-102$ \\
\hline Motor-Vehicle Accidents & 113 Category Recode: $115-123$ \\
\hline Suicide & 113 Category Recode: $124-126$ \\
\hline Homocide & 113 Category Recode: $127-130$ \\
\hline \hline
\end{tabular}

Notes: To group deaths into the above categories, I use either the actual ICD-10 code or the 113 cause recode of ICD-10 codes. 
Table A3

Unweighted Estimated Effects of Treatment Facilities on Drug-Induced Mortality

\begin{tabular}{lcccc}
\hline \hline & $(1)$ & $(2)$ & $(3)$ & $(4)$ \\
\hline Number of Facilities & $-0.058^{* * * *}$ & $-0.041^{* * *}$ & $-0.036^{* * *}$ & $-0.032^{* * * *}$ \\
& $(0.012)$ & $(0.011)$ & $(0.011)$ & $(0.011)$ \\
County and Year FE & & & & \\
State by Year FE & yes & yes & yes & yes \\
Demographic Controls & no & yes & yes & yes \\
Controls for Economic Conditions & no & no & yes & yes \\
Counties & 2,408 & no & no & yes \\
County-Year Observations & 24,068 & 24,068 & 2,408 & 2,408 \\
Mean & 8.504 & 8.504 & 8.504 & 24,068 \\
$\%$ Impact & 0.682 & 0.485 & 0.418 & 0.371 \\
\hline \hline
\end{tabular}

Notes: The dependent variable is a county's annual drug-induced mortality rate per 100,000 residents. The regressions include county fixed effects, state-by-year fixed effects and county-level controls for the unemployment rate, firm births, per-capita income, and the fraction of the county population that are: white, black, male, less than 18 years old, 18-64 years old, and greater than 64 years old. Number of Facilities is the count of treatment facilities in a county by year. Standard errors (in parentheses) are corrected for possible clustering at the county level.

* significant at $10 \%$;* significant at $5 \%$; ** significant at $1 \%$ 
Table A4

Poisson Estimates of the Effect of Treatment Facilities on Drug-Induced Mortality

\begin{tabular}{lcccc}
\hline \hline & $(1)$ & $(2)$ & $(3)$ & $(4)$ \\
\hline Number of Facilities & $-0.005 * * *$ & $-0.004 * * *$ & $-0.004 * * *$ & $-0.004 * * *$ \\
& $(0.001)$ & $(0.001)$ & $(0.001)$ & $(0.001)$ \\
County and Year FE & yes & yes & yes & yes \\
State-Specific Trend & no & yes & yes & yes \\
Demographic Controls & no & no & yes & yes \\
Controls for Economic Conditions & no & no & no & yes \\
& 2,383 & 2,383 & 2,383 & 2,383 \\
Counties & 23,818 & 23,818 & 23,818 & 23,818 \\
County-Year Observations & & & & \\
\hline \hline
\end{tabular}

Notes: The dependent variable is a county's annual number of drug-induced deaths. The regressions include county fixed effects, state-by-year fixed effects and county-level controls for the unemployment rate, firm births, per-capita income, and the fraction of the county population that are: white, black, male, less than 18 years old, 18-64 years old, and greater than 64 years old. Number of Facilities is the count of treatment facilities in a county by year. Huber-White robust estimates of the standard errors are in parentheses.

* significant at $10 \%$; * significant at $5 \%$; *** significant at $1 \%$ 
Table A5

The Effect of Facilities on Alcohol Poisoning Deaths Across Age

\begin{tabular}{lcccccccccc}
\hline \hline & $(1)$ & $(2)$ & $(3)$ & $(4)$ & $(5)$ & $(6)$ & $(7)$ & $(8)$ & $(9)$ & $(10)$ \\
& All & $<10$ & $10-19$ & $20-29$ & $30-39$ & $40-49$ & $50-59$ & $60-69$ & $70-79$ & $80+$ \\
\hline Number of Facilities & $-0.002^{* * *}$ & 0.000 & -0.000 & $-0.002^{*}$ & -0.001 & $-0.004 * * *$ & $-0.003^{* *}$ & $-0.004^{* * *}$ & $-0.002^{* * *}$ & -0.000 \\
& $(0.000)$ & $(0.000)$ & $(0.000)$ & $(0.001)$ & $(0.001)$ & $(0.001)$ & $(0.001)$ & $(0.001)$ & $(0.001)$ & $(0.001)$ \\
& & & & & & & & & & \\
Counties & 2,408 & 2,408 & 2,408 & 2,408 & 2,408 & 2,408 & 2,408 & 2,408 & 2,408 & 2,408 \\
County-Year Observations & 24,068 & 24,068 & 24,068 & 24,068 & 24,068 & 24,068 & 24,068 & 24,068 & 24,068 & 24,068 \\
Mean & 0.226 & 0.000888 & 0.0508 & 0.188 & 0.319 & 0.511 & 0.420 & 0.198 & 0.0725 & 0.0277 \\
\% Impact & 0.671 & 0.0508 & 0.940 & 0.822 & 0.247 & 0.715 & 0.645 & 1.776 & 3.237 & 1.219 \\
\hline \hline
\end{tabular}

Notes: The dependent variable is a county's age-adjusted alcohol-poisoning mortality rate per 100,000 residents. The regressions include county fixed effects, state-by-year fixed effects and county-level controls for the unemployment rate, firm births, per-capita income, and the fraction of the county population that are: white, black, male, less than 18 years old, 18-64 years old, and greater than 64 years old. Number of Facilities is the count of treatment facilities in a county by year. The estimates are weighted by county population and standard errors (in parentheses) are corrected for possible clustering at the county level.

$*$ significant at $10 \%$;** significant at $5 \%$;*** significant at $1 \%$ 
Table A6

Estimated Effects on Gender and Race Using Counties with Larger Black Populations

\begin{tabular}{lcccccc}
\hline \hline & $(1)$ & $\begin{array}{c}(2) \\
\text { blacks }\end{array}$ & $\begin{array}{c}(3) \\
\text { whites }\end{array}$ & $\begin{array}{c}(4) \\
\text { other }\end{array}$ & $\begin{array}{c}(5) \\
\text { male }\end{array}$ & $\begin{array}{c}(6) \\
\text { female }\end{array}$ \\
\hline Number of Facilities & $\begin{array}{c}-0.043^{* * *} \\
(0.009)\end{array}$ & $\begin{array}{c}-0.067^{* * *} \\
(0.022)\end{array}$ & $\begin{array}{c}-0.045^{* * *} \\
(0.011)\end{array}$ & $\begin{array}{c}-0.002 \\
(0.006)\end{array}$ & $\begin{array}{c}-0.059^{* * *} \\
(0.011)\end{array}$ & $\begin{array}{c}-0.028^{* * * *} \\
(0.007)\end{array}$ \\
& & & & & & \\
Counties & 802 & 802 & 802 & 802 & 802 & 802 \\
County-Year Observations & 8,020 & 8,020 & 8,020 & 8,020 & 8,020 & 8,020 \\
Mean & 9.479 & 8.157 & 10.56 & 2.221 & 12.63 & 6.503 \\
\% Impact & 0.452 & 0.822 & 0.426 & 0.0844 & 0.466 & 0.424 \\
\hline \hline
\end{tabular}

Notes: The sample is restricted to counties within the highest tercile of proportion of county residents that are black (greater than 8 percent black). The dependent variables are a county's annual demographicspecific drug-induced mortality rate per 100,000 residents corresponding to each column heading. The regressions include county fixed effects, state-by-year fixed effects and county-level controls for the unemployment rate, firm births, per-capita income, and the fraction of the county population that are: white, black, male, less than 18 years old, 18-64 years old, and greater than 64 years old. Number of Facilities is the count of treatment facilities in a county by year. The estimates are weighted by county population and standard errors (in parentheses) are corrected for possible clustering at the county level.

* significant at $10 \%$;* significant at $5 \% ; * * *$ significant at $1 \%$ 
Table A7

Additional Heterogeneity Across County Characteristics

\begin{tabular}{|c|c|c|c|c|c|}
\hline & \multirow[t]{2}{*}{$\begin{array}{c}(1) \\
\text { All Counties } \\
\end{array}$} & \multicolumn{2}{|c|}{$\begin{array}{c}(2) \\
\text { Drug-Induced Mortality }\end{array}$} & \multicolumn{2}{|c|}{$\begin{array}{c}(4) \\
\text { Per-Capital Treatment Facilities }\end{array}$} \\
\hline & & Low & High & Low & High \\
\hline Number of Facilities & $\begin{array}{c}-0.039 * * * \\
(0.005)\end{array}$ & $\begin{array}{l}-0.023 * * * \\
(0.007)\end{array}$ & $\begin{array}{c}-0.038^{* * *} \\
(0.013)\end{array}$ & $\begin{array}{c}-0.031 * * * \\
(0.004)\end{array}$ & $\begin{array}{c}-0.038 * * * \\
(0.013)\end{array}$ \\
\hline Counties & 2,408 & 1,204 & 1,204 & 1,204 & 1,204 \\
\hline County-Year Observations & 24,068 & 12,036 & 12,032 & 12,036 & 12,032 \\
\hline $\begin{array}{l}\text { Mean } \\
\text { \% Impact }\end{array}$ & $\begin{array}{l}9.399 \\
0.419\end{array}$ & $\begin{array}{l}5.449 \\
0.416\end{array}$ & $\begin{array}{l}11.61 \\
0.325\end{array}$ & $\begin{array}{l}5.633 \\
0.550\end{array}$ & $\begin{array}{l}12.41 \\
0.303\end{array}$ \\
\hline
\end{tabular}

Notes: The dependent variable is a county's annual drug-induced mortality rate per 100,000 residents. The regressions include county fixed effects, state-by-year fixed effects and county-level controls for the unemployment rate, firm births, per-capita income, and the fraction of the county population that are: white, black, male, less than 18 years old, 18-64 years old, and greater than 64 years old. Number of Facilities is the count of treatment facilities in a county by year. The estimates are weighted by county population and standard errors (in parentheses) are corrected for possible clustering at the county level.

$*$ significant at $10 \% ; * *$ significant at $5 \% ; * * *$ significant at $1 \%$ 
Table A8

Estimated Effects of Treatment Facilities on Other Causes of Death

\begin{tabular}{|c|c|c|c|c|c|c|c|c|c|c|c|}
\hline & $\begin{array}{c}(1) \\
\text { Drug-Induced } \\
\end{array}$ & $\begin{array}{c}(2) \\
\text { All Deaths }\end{array}$ & $\begin{array}{c}(3) \\
\text { Non Drug-Induced } \\
\end{array}$ & $\begin{array}{c}(4) \\
\text { Cardiov } \\
\end{array}$ & $\begin{array}{c}(5) \\
\text { Cancer } \\
\end{array}$ & $\begin{array}{c}\text { (6) } \\
\text { Infection / Immune }\end{array}$ & $\begin{array}{c}(7) \\
\text { Disease }\end{array}$ & $\begin{array}{c}(8) \\
\text { MV Acc }\end{array}$ & $\begin{array}{c}(9) \\
\text { Suicide } \\
\end{array}$ & $\begin{array}{c}(10) \\
\text { Homicide }\end{array}$ & $\begin{array}{l}(11) \\
\text { Other }\end{array}$ \\
\hline \multicolumn{12}{|l|}{ Panel A: All Ages } \\
\hline Number of Facilities & $\begin{array}{c}-0.039 * * * \\
(0.005)\end{array}$ & $\begin{array}{c}-0.138^{* *} \\
(0.067)\end{array}$ & $\begin{array}{l}-0.119^{*} \\
(0.067)\end{array}$ & $\begin{array}{c}0.004 \\
(0.029)\end{array}$ & $\begin{array}{l}-0.005 \\
(0.015)\end{array}$ & $\begin{array}{c}-0.033 * * * \\
(0.010)\end{array}$ & $\begin{array}{l}-0.031 \\
(0.019)\end{array}$ & $\begin{array}{c}0.001 \\
(0.002)\end{array}$ & $\begin{array}{c}-0.008 * * * \\
(0.002)\end{array}$ & $\begin{array}{c}-0.019 * * * \\
(0.003)\end{array}$ & $\begin{array}{l}-0.008 \\
(0.013)\end{array}$ \\
\hline $\begin{array}{l}\text { Counties } \\
\text { County-Year Observations }\end{array}$ & $\begin{array}{c}2,408 \\
24,068\end{array}$ & $\begin{array}{c}2,408 \\
24,068\end{array}$ & $\begin{array}{c}2,408 \\
24,068\end{array}$ & $\begin{array}{c}2,408 \\
24,068\end{array}$ & $\begin{array}{c}2,408 \\
24,068\end{array}$ & $\begin{array}{c}2,408 \\
24,068\end{array}$ & $\begin{array}{c}2,408 \\
24,068\end{array}$ & $\begin{array}{c}2,408 \\
24,068\end{array}$ & $\begin{array}{c}2,408 \\
24,068\end{array}$ & $\begin{array}{c}2,408 \\
24,068\end{array}$ & $\begin{array}{c}2,408 \\
24,068\end{array}$ \\
\hline $\begin{array}{l}\text { Mean } \\
\% \text { Impact }\end{array}$ & $\begin{array}{l}9.399 \\
0.419\end{array}$ & $\begin{array}{c}828.4 \\
0.0167\end{array}$ & $\begin{array}{c}822.1 \\
0.0144\end{array}$ & $\begin{array}{c}301.2 \\
0.00121\end{array}$ & $\begin{array}{c}195.3 \\
0.00274\end{array}$ & $\begin{array}{l}26.90 \\
0.121\end{array}$ & $\begin{array}{c}151.0 \\
0.0205\end{array}$ & $\begin{array}{c}14.70 \\
0.00821\end{array}$ & $\begin{array}{c}9.526 \\
0.0830\end{array}$ & $\begin{array}{l}6.261 \\
0.309\end{array}$ & $\begin{array}{c}83.47 \\
0.00920\end{array}$ \\
\hline \multicolumn{12}{|l|}{ Panel B: Ages less than 65} \\
\hline Number of Facilities & $\begin{array}{c}-0.043^{* * *} * \\
(0.005)\end{array}$ & $\begin{array}{c}-0.121 * * * \\
(0.020)\end{array}$ & $\begin{array}{c}-0.078^{* * *} * \\
(0.019)\end{array}$ & $\begin{array}{l}-0.009 \\
(0.006)\end{array}$ & $\begin{array}{c}-0.006 \\
(0.005)\end{array}$ & $\begin{array}{c}-0.018^{* * *} * \\
(0.007)\end{array}$ & $\begin{array}{c}-0.011 * * * \\
(0.003)\end{array}$ & $\begin{array}{c}0.001 \\
(0.003)\end{array}$ & $\begin{array}{c}-0.011 \text { *** } \\
(0.002)\end{array}$ & $\begin{array}{c}-0.023 * * * \\
(0.004)\end{array}$ & $\begin{array}{l}-0.000 \\
(0.010)\end{array}$ \\
\hline $\begin{array}{l}\text { Counties } \\
\text { County-Year Observations }\end{array}$ & $\begin{array}{c}2,408 \\
24,068\end{array}$ & $\begin{array}{c}2,408 \\
24,068\end{array}$ & $\begin{array}{c}2,408 \\
24,068\end{array}$ & $\begin{array}{c}2,408 \\
24,068\end{array}$ & $\begin{array}{c}2,408 \\
24,068\end{array}$ & $\begin{array}{c}2,408 \\
24,068\end{array}$ & $\begin{array}{c}2,408 \\
24,068\end{array}$ & $\begin{array}{c}2,408 \\
24,068\end{array}$ & $\begin{array}{c}2,408 \\
24,068\end{array}$ & $\begin{array}{c}2,408 \\
24,068\end{array}$ & $\begin{array}{c}2,408 \\
24,068\end{array}$ \\
\hline $\begin{array}{l}\text { Mean } \\
\% \text { Impact }\end{array}$ & $\begin{array}{l}10.33 \\
0.418\end{array}$ & $\begin{array}{c}249.9 \\
0.0483\end{array}$ & $\begin{array}{c}239.6 \\
0.0324\end{array}$ & $\begin{array}{c}58.15 \\
0.0154\end{array}$ & $\begin{array}{c}67.20 \\
0.00940\end{array}$ & $\begin{array}{l}11.54 \\
0.153\end{array}$ & $\begin{array}{c}20.55 \\
0.0528\end{array}$ & $\begin{array}{c}15.98 \\
0.00577\end{array}$ & $\begin{array}{l}9.550 \\
0.116\end{array}$ & $\begin{array}{l}7.588 \\
0.309\end{array}$ & $\begin{array}{c}50.13 \\
0.000550\end{array}$ \\
\hline
\end{tabular}

Notes: The dependent variable is a county's annual mortality rate per 100,000 residents corresponding to each column title. The regressions include county fixed effects, state-by-year fixed effects and county-level controls for the unemployment rate, firm births, per-capita income, and the fraction of the county population that are: white, black, male, less than 18 years old, 18-64 years old, and greater than 64 years old. Number of Facilities is the count of treatment facilities in a county by year. The estimates are weighted by county population and standard errors (in parentheses) are corrected for possible clustering at the county level.

* significant at $10 \% ; * *$ significant at $5 \% ; * * *$ significant at $1 \%$ 
Table A9

Estimated Effects by Facility Size

\begin{tabular}{lcc}
\hline \hline & Estimate & $\begin{array}{c}\text { Fraction of all Facilities } \\
\text { (mean) }\end{array}$ \\
\hline Facilities with 1-4 employees & $\begin{array}{c}-0.019 \\
(0.016)\end{array}$ & 0.33 \\
Facilities with 5-9 employees & $\begin{array}{c}-0.027 * \\
(0.014)\end{array}$ & 0.21 \\
Facilities with 10-19 employees & $-0.031^{* *}$ & 0.24 \\
Facilities with 20-49 employees & $-0.081 * * *$ & \\
Facilities with 50-99 employees & $(0.019)$ & 0.16 \\
Facilities with 100+ employees & $\begin{array}{c}(0.032 \\
0.034)\end{array}$ & 0.06 \\
Counties & $(0.070)$ & 0.03 \\
County-Year Observations & 2,408 & \\
\hline \hline
\end{tabular}

Notes: The dependent variable is the county-level drug-induced mortality rate per 100,000. The regressions include county-fixed effects, state-by-year fixed effects and county-level controls for the unemployment rate, firm births, per-capita income, and the fraction of the county population that are: white, black, male, less than 18 years old, 18-64 years old, and greater than 64 years old. The estimates are weighted by county population and standard errors (in parentheses) are corrected for possible clustering at the county level. 